\title{
Examining the Co-Occurrence of Engagement and Self- Referencing in the Context of Narrative Persuasion
}

Julia K Weiss

Follow this and additional works at: https://researchrepository.wvu.edu/etd

\section{Recommended Citation}

Weiss, Julia K, "Examining the Co-Occurrence of Engagement and Self-Referencing in the Context of Narrative Persuasion" (2018). Graduate Theses, Dissertations, and Problem Reports. 7275.

https://researchrepository.wvu.edu/etd/7275

This Dissertation is protected by copyright and/or related rights. It has been brought to you by the The Research Repository @ WVU with permission from the rights-holder(s). You are free to use this Dissertation in any way that is permitted by the copyright and related rights legislation that applies to your use. For other uses you must obtain permission from the rights-holder(s) directly, unless additional rights are indicated by a Creative Commons license in the record and/ or on the work itself. This Dissertation has been accepted for inclusion in WVU Graduate Theses, Dissertations, and Problem Reports collection by an authorized administrator of The Research Repository @ WVU.

For more information, please contact researchrepository@mail.wvu.edu. 


\title{
Examining the Co-Occurrence of Engagement and Self-Referencing in the Context of Narrative Persuasion
}

\author{
Julia K. Weiss
}

\author{
Dissertation submitted \\ to the Eberly College of Arts and Sciences \\ at West Virginia University \\ in partial fulfillment of the requirements for the degree of \\ Doctor of Philosophy in \\ Communication Studies
}

\author{
Elizabeth L. Cohen, Ph.D., Chair \\ Jaime Banks, Ph.D. \\ Nicholas D. Bowman, Ph.D. \\ Megan R. Dillow, Ph.D. \\ Julia D. Fraustino, Ph.D. \\ Department of Communication Studies
}
Morgantown, West Virginia
2018

Keywords: narrative engagement, self-referencing, narrative persuasion, stories, sexually transmitted infections

Copyright 2018 Julia K. Weiss 


\begin{abstract}
Examining the Co-Occurrence of Engagement and Self-Referencing

in the Context of Narrative Persuasion
\end{abstract}

Julia K. Weiss

Current theorizing in narrative persuasion demonstrates that stories can be used as a means to shift attitudes, behavioral intentions, and the like, which can be utilized as a form of health communication. Likewise, empirical evidence on self-referencing - a process through which individuals relate environmental stimuli to themselves demonstrates that thinking about the self in regards to stimuli such as narratives can make the messages in those stimuli more persuasive. While both of these can occur in response to narratives and can yield positive persuasive outcomes, there is theoretical reason to believe that these two processes cannot co-occur: Engagement is conceptualized as a process through which one loses awareness of themselves, whereas self-referencing is conceptualized as having an awareness of how things in the environment relate to oneself. The primary goal of this study was to determine if these two processes are actually unable to co-occur simultaneously. In addition, differences that may exist in persuasive power between narrative engagement and self-referencing in the context of narratives were unknown. As such, the second goal of this study was to uncover potential differences in how narrative engagement and self-referencing affect persuasive outcomes. Finally, the bulk of research on both narrative engagement and self-referencing tends to focus on these processes as they occur during narrative consumption, but there is mounting evidence that the post-narrative exposure period is important for persuasion as well. Even if individuals cannot self-reference during a narrative, they may be able to do so after. Therefore, the final goal of the current study was to determine to what extent people self-reference after a narrative when they are encouraged to self-reference during a narrative compared to when they are encouraged to be fully engaged with the narrative. Using an episode of the television series Girls that contains a narrative about sexual health, a between-subjects experiment was conducted with 223 undergraduate students that were randomly assigned to one of four conditions: self-referencing directions, narrative engagement directions, mixed directions, and no directions. The narrative engagement manipulation was unsuccessful. However, participants in both the selfreferencing condition and the mixed instructions condition reported engaging in more self-referencing than the other conditions. Participants in these conditions did not report less narrative engagement as a result. This suggests that self-referencing is compatible with narrative engagement. There were no differences in persuasive outcomes between the conditions. Because there was no inclusion of a control stimulus, it is unknown whether the episode was persuasive. Likewise, there were no differences in the amount of counterarguing viewers engaged in between the conditions, indicating that selfreferencing did not prompt defensive processing of the message. Finally, there were no difference in the amount of self-referencing viewers generated after the episode between the conditions. The results are discussed in light of narrative persuasion theory, application, and opportunities for future research. 


\section{ACKNOWLEDGEMENTS}

To my advisor, Elizabeth Cohen - thank you for taking me on as your first advisee. It has been quite a ride! Through all of the hoops I had to jump through you have always advocated for me, talked rational sense into me, and worked to boost my selfconfidence. Thank you for working so hard over the years to shape me into the scholar I am. I will forever remember to "fix my face" in important situations and to be the best department member (in a shark onesie) that I can be wherever I work. To my committee, Drs. Dillow, Bowman, Banks, Fraustino, and Sharabi - thank you all for your assistance on this project. Your comments and suggestions at each stage have certainly made this study better! I value each of your contributions and the time we spent working together.

To my husband, Jonathan - thank you for always supporting me as I worked through this degree. You have been there for me these past three years and you have certainly seen it all! Whenever I felt like I wanted to quit (which is more often than I would like to admit), I always heard you behind me saying my favorite thing: "You are a warrior”. That - and your ridiculous level of optimism - helped keep me pushing through the rough patches. In this short amount of time, we moved in together, got married, survived your deployment, and now we have a baby on the way. This degree was not easy for me to get especially with all of these changes in our relationship happening at the same time. However, you never stopped encouraging me or loving me. Now I got it: “That GD Ph.D.”!

To my father, “The Great David Weiss” - needless to say, this hard task would have been infinitely harder without your support. When I think back on the past few years, I think about all of the times I was down for various reasons and how you were always there to lend a helping hand (or ear). I think about our Sunday phone calls and 
how you were always curious about the progress I was making. Whenever good things happened for me, you were happy, and whenever bad things happened, you were ready to kick some booty for me - daddy-style. It is hard to accomplish the goal I set for myself of becoming a doctor alone, but with your support, I never felt I was doing it alone. Your love knows no bounds and I will always appreciate what you have done for me. A last request: since you are the "whale of the casino" and I finally finished this degree up, can I please be the "whale of academia”? It would mean a lot to me!

Finally, to the friends I have made over these past three years - you all rock! Christine - wow. What is a Mork without her Spogooter and what are friends without SUITS? We always say when we look back at graduate school, we do not want to think about the work, but the good times we had instead. And lady, we had some good times. We have a reputation around town as the "Prosecco Girls", and that might actually be the coolest title we took from all of this - who needs to be "Doctor" anyway? I am glad we have always had each other and will continue to as we managed to get jobs next to each other next year! To Joe - thank you for being the most giving and selfless friend I have ever had. You have spent countless hours teaching me statistics, talking me through my projects, and just having fun with me. Can I share my degree with you? Thanks to you, I will always remember to "be sweet”, but I probably will not remember anything about statistics (it is a "me problem” and I am sure I will call you about stats soon or else I might melt under a desk somewhere). You are a wonderful person and friend! Finally, Jordan and Hannah, my long-lost chalupas - you both have kept me smiling since day one. Even though you have been gone a while, we still manage to talk several times a week, which is awesome. Thanks for always supporting me in this journey! \#OGSupahs 
TABLE OF CONTENTS

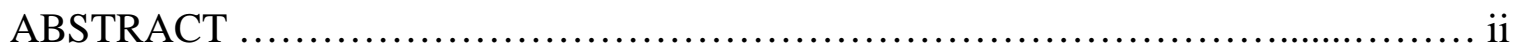

ACKNOWLEDGEMENTS ........................................................ ii

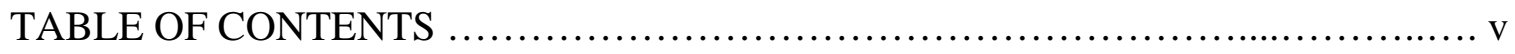

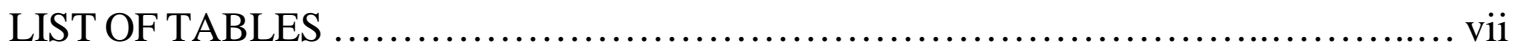

CHAPTER I: INTRODUCTION ................................................. 1

Perspectives of Narrative Persuasion Theory ...................................... 4

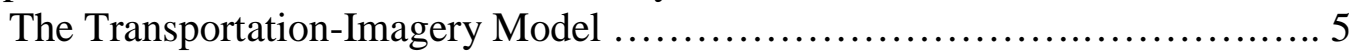

The Extended-Elaboration Likelihood Model .................................. 7

Narrative Engagement - A Mental Models Approach to Involvement ............ 8

The Relationship between Transportation and Engagement ................... 10

The Entertainment Overcoming Resistance Model ............................. 10

Conclusions for Narrative and Persuasion .................................... 11

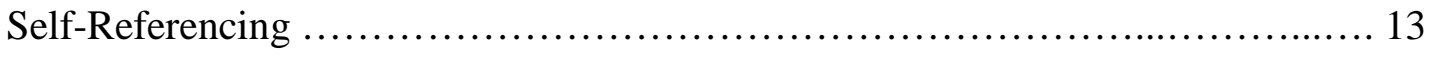

Effects of Self-Referencing on Recall and Persuasion .......................... 14

Self-Referencing and Narrative Persuasion ....................................... 17

The Tradeoff between Narrative Engagement and Self-Referencing ................... 19

Self-Referencing and Counterarguing ........................................... 22

The Post-Exposure Period after Narratives and Its Persuasive Potential .................. 23

Self-Referencing in the Post-Exposure Period ................................ 26

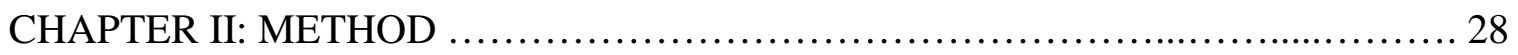

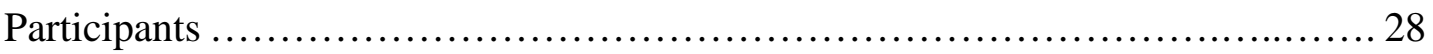

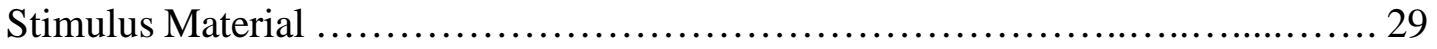

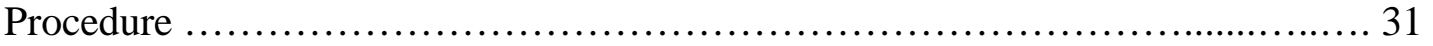

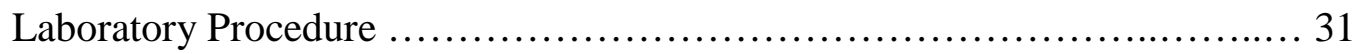

Experimental Conditions .............................................. 32

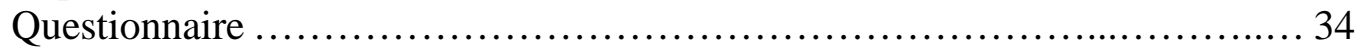

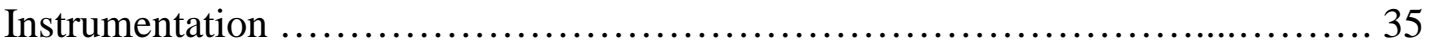

Narrative Engagement ..................................................... 35

Self-Referencing During Viewing ........................................... 36

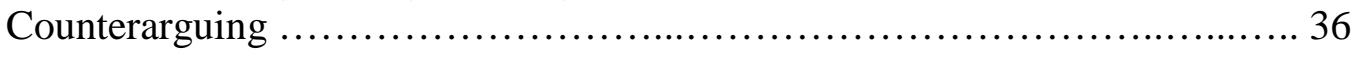

Attitudes towards Talking to Partners about STI Status ....................... 37

Behavioral Intentions to Talk to Partners about STI Status ..................... 37

Self-Referencing After Viewing .......................................... 38

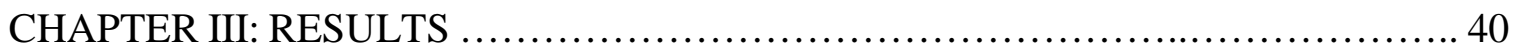

Descriptive and Preliminary Analyses ............................................ 40

Manipulation Checks …................................................ 42

Comparison Condition Analyses .......................................... 44

Hypothesis Tests ............................................................. 46

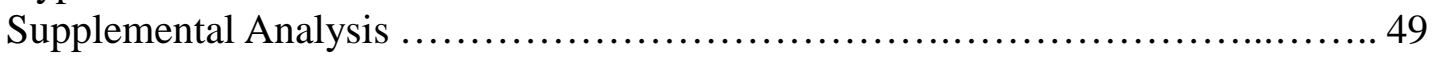


CHAPTER IV: DISCUSSION ............................................. 57

The Co-Occurrence of Narrative Processes ...................................... 60

The Impact of Self-Referencing During a Narrative on Persuasion .................. 65

The Relationship between Self-Referencing and Counterarguing ................... 68

Self-Referencing After a Narrative .......................................... 70

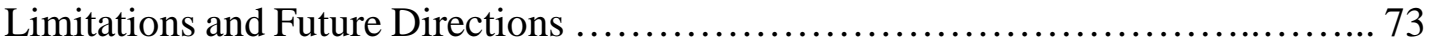

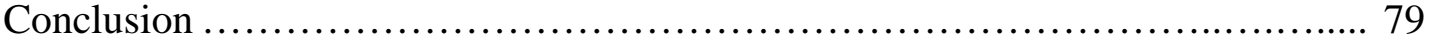

REFERENCES ......................................................... 81

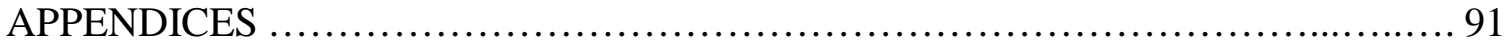




\section{LIST OF TABLES}

Table 1. Zero-Order Correlation Matrix

41

Table 2. Means, Standard Deviations, and Pairwise Comparisons of Narrative

Engagement between the Experimental and Comparison Conditions 45

Table 3. Means, Standard Deviations, and Pairwise Comparisons of Self-Referencing between the Experimental and Comparison Conditions ............................. 46

Table 4. Hierarchical Regression Predicting Positive Attitudes towards Talking to Past

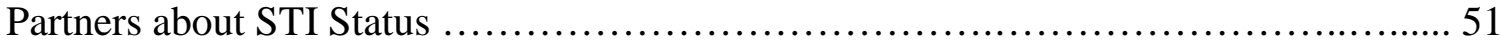

Table 5. Hierarchical Regression Predicting Positive Attitudes towards Talking to Current Partners about STI Status .............................................. 52

Table 6. Hierarchical Regression Predicting Positive Attitudes towards Talking to Partners about STI Status in General ............................................ 53

Table 7. Hierarchical Regression Predicting Intentions to Disclose STI Status to Past

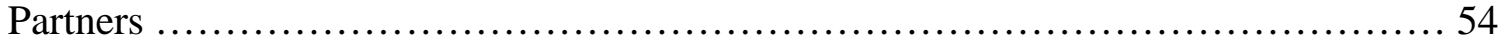

Table 8. Hierarchical Regression Predicting Intentions to Disclose STI Status to Current

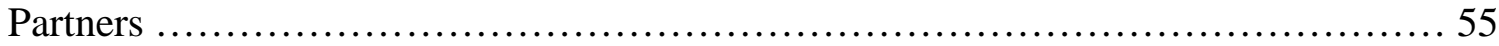

Table 9. Hierarchical Regression Predicting Intentions to Talk to Partners about STIs in General ............................................................... 56 


\section{CHAPTER I}

\section{Introduction}

Extant literature, frameworks, and theories of narrative persuasion continuously demonstrate that stories have the power to change the knowledge, attitudes, values, intentions, and behaviors that people hold (e.g., Busselle \& Bilandzic, 2009; Green and Brock, 2000, 2002; Moyer-Gusé \& Nabi, 2010; Nabi, 2015; Nabi \& Green, 2015; Slater \& Rouner, 2002; Strange \& Leung, 1999). Further, they assert that narratives are uniquely equipped to persuade when compared to more traditional, overt persuasive messages. What makes narratives so immensely successful at persuading their audiences is a topic of scholarly interest. Pioneers of narrative persuasion research such as Green and Brock (2000) posit that total absorption and occupation with a narrative (i.e., transportation) produces the conditions for persuasion, and they propose that several mechanism may be at work including a loss of access to real-world facts, assumptions, and beliefs as well as intense emotional connections to characters and emotional reactions to events in stories. Building off of transportation, Busselle and Bilandzic (2009) propose that understanding narratives involves great concentration, which accompanies presence within the narrative world and emotional reactions as well. These and other major theories and models of narrative persuasion are in agreement that stories have the power to persuade by absorbing narrative consumers.

As mentioned, there is a copious amount of research exploring absorption into narrative worlds and how this involvement can yield persuasive outcomes. There is considerably less exploration of another potential mechanism for narrative persuasion, which is self-referencing. Self-referencing is when an individual takes information from 
their environment and contemplates how the information relates to the self and past experiences (Rogers, Kupier, \& Kirker, 1977), and is a concept that has been mainly studied in the context of more traditional, rhetorical persuasive messages (e.g., advertisements). The role of self-referencing in narrative persuasion is not yet clearly defined. However, given the important role of self-referencing in overtly persuasive messages as well as the persuasive potential of narratives, examining how people relate narratives to the self and the subsequent effects of that self-referencing is an important area to study. In the few studies that have examined self-referencing and narrative persuasion (e.g., Chen, Bell, \& Taylor, 2016, 2017; Dunlop, Wakefield, \& Kashima, 2010), thinking about how stories and their messages relate to the self has been shown to have persuasive potential. For example, self-referencing has been shown to act as a mediator between both identifying with characters and perceptions of susceptibility to health issues (Chen, Bell, \& Taylor, 2016) and between identification and perceived persuasiveness of messages (Chen, Bell, \& Taylor, 2017).

Collectively, the aforementioned bodies of research indicate that both engagement with narratives and self-referencing facilitate narrative persuasion. Yet theoretically, these two mechanisms for persuasion should not be able to co-occur—at least not simultaneously. Conceptually, narrative engagement is defined by a loss of selfawareness while a reader or viewer adopts a perspective merged with the story world (Busselle \& Bilandzic, 2009; Green \& Brock, 2000). On the contrary, self-referencing definitionally involves a heightened level of self-awareness, occurring when individuals think about how what they are taking in in their environment relates to the self (Rogers, Kupier, \& Kirker, 1977). In this way, engagement and self-referencing are conflicting 
processes. While thinking about the self, people should not also be able to lose themselves and become completely absorbed by the narrative.

In addition, it is not clear how self-referencing may come into play once an individual has reached the conclusion of a narrative and has time to reflect on their narrative experience. During this post-exposure period, it is possible that given the time to reflect back on the narrative, those who were previously engaged may now be freer to make connections from their own lives back to the story. This self-referencing after the narrative could also impact persuasive outcomes associated with the story. Much of the previously mentioned narrative persuasion research is focused on the mechanisms that are associated with engagement during exposure, leaving this post-exposure period relatively unexplored.

Given these current gaps in narrative persuasion literature exist, this study seeks to fill these gaps by accomplishing three main goals. First, the study explores how selfreferencing during a narrative impacts story-consistent persuasive outcomes. To do this, the effects of being told to engage with a story on persuasive outcomes (i.e., adopting story-consistent attitudes and behavioral intentions) are compared to the effects of being told to self-reference on these outcomes. Second, this study tests the assertion that narrative engagement and self-referencing in response to narratives are, in fact, processes that cannot co-occur. Although both processes are no doubt important for persuasion, it is argued that, conceptually speaking, they are mutually exclusive. Assuming that engagement and self-referencing cannot co-occur in the moment, this raises the important question of which process is more conducive for persuasion. Finally, even if narrative engagement and self-referencing cannot co-occur during narrative exposure, it stands to 
reason absorbed individuals may engage in self-referencing after the story. To examine this possibility, this study will look at whether engagement during the story impacts thoughts about the self after the story is over as a third goal. On a practical level, the results of this study will inform the design of persuasive narrative interventions by shedding light on the relative merits of encouraging narrative engagement and selfreferencing. Finally, theoretically, the results of this study will demonstrate whether these two important and well-established mechanisms for persuasion operate simultaneously or separately when people are exposed to narratives.

\section{Perspectives of Narrative Persuasion Theory}

Narratives are considered to be a tool with great persuasive power due to their ability to absorb people into storylines, which has many beneficial consequences that are explicated below. According to Green and Brock (2000), a narrative is a story that is structured to have a beginning, middle, and end. It is a story that raises questions that are unanswered and conflicts that are unresolved, and creates an alternative world where the characters may experience and then later solve a crisis. Similarly, Bruner (1986) remarks that stories deal with human-like interactions and follow protagonists through the actions, changes, and consequences of their lives. Stories are a powerful way to convey information, often in an entertaining way as the worlds created by the narrative engage people both in emotional and cognitive ways (Busselle \& Bilandzic, 2008). Although perspectives do vary slightly in terms of their proposed mechanisms for persuasion, all are in agreement that narratives have persuasive utility. Perspectives that are particularly relevant to the proposed study are discussed further. 


\section{The Transportation-Imagery Model}

Stories have long been recognized as persuasive tools that can alter peoples' attitudes and beliefs (Green \& Brock, 2000; Strange \& Leung, 1999). One of the first formal models of narrative persuasion was the Transportation-Imagery Model (Green \& Brock, 2000), which proposes that narrative persuasion is a result of transportation, a process where all mental systems become fixated on the events and characters of a narrative causing a person to "transport” into the world of the story (Gerrig, 1993; Green \& Brock, 2000; 2002). There are several consequences of becoming transported into the story world (Green \& Brock, 2000). Becoming wrapped up in the world of the narrative and, in essence, being lost in a story, results in a loss of access to one's real-world surroundings and thoughts. This loss of reality occurs on both a physical level and psychological level in what Green and Brock refer to as "a subjective distancing from reality” (p. 702). People who are transported also tend to have strong emotional reactions as well as experience motivations as the narrative unfolds. These emotions and motivations may be a result of taking on the perspectives of the protagonists thereby acquiring the characters' goals and motivations (see Cohen, 2001), or a result of being so absorbed into the story that the individual consuming the narrative is motivated to think about how the story is unfolding, what will happen next, and what could have gone differently (see Gerrig, 1993; Green \& Brock, 2000). Green, Brock, and Kaufman (2004) assert that narrative absorption is akin to a flow-like state ${ }^{1}$, a pleasurable experience

\footnotetext{
${ }^{1}$ Csikszentmihalyi (1990) conceptualizes flow as an enjoyable state that occurs when a person engages in an activity that is challenging but not too difficult for a person's skill
} 
resulting from intense concentration, participation in alternative reality, and immersion in an activity that draws one away from their physical and psychological environment.

Green and Brock (2000) present three reasons that transportation can facilitate persuasion. First, recalling that a transported person is not paying attention to the realworld and is instead engaged in the story, absorbed individuals may decrease the amount of negative cognitive responding they perform to the story’s messages. Unlike overtly rhetorical persuasive messages, people who are transported are less likely to counterargue the points made in a story. When people are counterarguing, they are not likely to be persuaded by messages and counterarguing is far less likely in response to narratives than rhetoric. In this way, it becomes easier for consumers to accept claims put forth by the story and easier to change an individual's beliefs. This is thought to occur because people accept fictional stories and messages as they consume narratives because there is some entertainment value that relies on this suspension of disbelief and acceptance of the storyworld. Second, narratives tell of the trials, success, and failures of other people and therefore, in many ways, mimics the reality that people know. That is, characters in stories go through many of the same experiences as the people consuming these stories. As such, narratives may be much more similar to real experiences than rhetorical messages giving stories the potential to be more impactful on attitudes, as direct

level, when there is immediate feedback about the progress being made in the task, and there is clear proximal goals. If all three of these conditions are met, the individual is said to enter a subjective state where they are intensely focused, lose awareness of the self as a social actor, lose sense of time, and find the task to be intrinsically rewarding. 
experiences can shape attitudes. Third, Green and Brock assert that stories result in feelings towards and with the characters. As people attach themselves to the protagonists they experience emotions along with these characters, which is thought to then influence the attitudes and beliefs they hold.

\section{The Extended-Elaboration Likelihood Model}

The Extended-Elaboration Likelihood Model (E-ELM; Slater \& Rouner, 2002) is another model developed to explain why persuasion occurs in response to persuasive messages embedded in entertainment fare. In the original Elaboration Likelihood Model (ELM), Petty and Cacioppo (1986) explain that individuals will vary in how likely they will be to engage in issue-relevant thinking (i.e., elaboration) when presented with messages, which is said to depend on their motivation and ability to process a message. Persuasion is thought to occur under two routes, the central and the peripheral route. People processing under the central route think about and scrutinize messages whereas people processing under the peripheral route rely on heuristics rather than deeper elaboration. Slater and Rouner (2002) argue that these patterns of the traditional ELM may only hold for obviously persuasive messages, but not entertaining messages like stories, because people have different motivations for these types of messages. Specifically, the model is premised on the idea that, unlike overtly persuasive content, people process entertaining narratives for the sake of enjoyment rather than evaluating the merits of a message, and therefore are persuaded through routes other than cognitive elaboration. Hence, the E-ELM posits that involvement with narratives in entertainment media depends on how well narrative serves the goal of providing entertainment. 
Like the Transportation Imagery Model (Green \& Brock, 2000), the E-ELM (Slater \& Rouner, 2002) argues that narrative involvement is the route to persuasion that works by reducing people’s ability to counterargue against persuasive messages embedded in the story. In the E-ELM, involvement is a product of perceived homophily with characters, interest in the plot, and from non-obvious persuasive messages. A reduction to counterarguing is proposed to occur because arguing against messages presented in narratives would decrease engagement with these elements and take away from its entertainment value (Dal Cin, Zanna, \& Fong, 2004).

\section{Narrative Engagement - A Mental Models Approach to Involvement}

In a more recent explanation of the narrative persuasion process, Busselle and Bilandzic (2008; 2009) propose that a transportation state, what they refer to as narrative engagement, occurs when individuals construct models of meaning to represent stories they encounter. People do this by thinking about the text, about prior general knowledge they possess, and about genre-specific knowledge that they know from past experiences with the genre. In this way, they come to understand the stories they are consuming. These mental models are cognitive structures consisting of different ideas and associations that people use to make sense of how things work in their environment. As they read or watch a story, people construct new mental models and integrate information from the story into their existing mental models in order to comprehend the narrative. This a constant comprehension process that occurs throughout narrative exposure.

Busselle and Bilandzic (2008) argue that narrative engagement occurs as a result of the generation of any one of three types of mental models. Situation models involve following the thread of the story, the spatial setting, and the chronological sequence of 
the story. Story-world models represent, “place, time period, and general contemporary state of affairs” (p. 259) within the story. Finally, character models, which are developed from prior knowledge and stereotypes, are ideas about the characters’ identities, traits, motivations, and goals. The authors further propose that in order to be engaged with stories, people need to shift the center of their experience from the real-world to the story-world through the process of deictic shifting (see Duchan, Bruder, \& Hewitt, 1995). The consequences of this shift are taking on the perspectives of characters, adopting their views, goals, and, biases (i.e., identification) and the sensation of experiencing what happens in the story-world directly.

According to Busselle and Bilandzic (2009), the narrative engagement experience consists of four dimensions: narrative presence, narrative understanding, attentional focus, and emotional engagement. Presence refers to feeling that the narrative world is closer than the real-world and is thought to be explained by flow, the complete focus on an activity and subsequent loss of real-worlds access. Narrative presence is the sensation of being inside the narrative world as a result of perspective taking and comprehension. Related to presence and flow are the ease of cognitive access, which is the degree to which individuals can maintain focus and not experience difficulty in processing, and involvement, which is the conscious feeling of being absorbed in the narrative. The second dimension, narrative understanding is focused on the ease of comprehending a story and the ease of constructing mental models of meaning as discussed previously. Attentional focus, the third dimension, is demonstrated by how much attention is paid to a narrative and the lack of awareness that one is focusing their attention. Finally, 
emotional engagement occurs when people are feeling sympathy and empathy with the characters and when the narrative impacts them emotionally in general.

\section{The Relationship between Transportation and Engagement}

Although conceptually, transportation and narrative engagement more-or-less describe the same phenomenon of story immersion, they have been operationalized differently. Quintero-Johnson and Sangalang (2017) compared the transportation scale (Green \& Brock, 2000) and the narrative engagement scale (Busselle \& Bilandzic, 2009) in terms of how each may measure different parts of the narrative persuasion process in terms of a person's involvement with a narrative. In their study, transportation directly influenced both perceived relevance of the health topic in the narrative as well as story consistent attitudes and behavioral intentions, while narrative engagement did not. Instead, the narrative understanding subscale of the engagement scale was positively related to attitude change through its negative relationship with reactance. Each of these scales have utility and capture different but important aspects of the narrative persuasion process. The authors conclude that whereas the transportation measure is useful for capturing more affective experiences, the narrative engagement scale may be better for measuring attention and understanding a narrative.

\section{The Entertainment Overcoming Resistance Model}

The Entertainment Overcoming Resistance Model (EORM; Moyer-Gusé, 2008; Moyer-Gusé \& Nabi, 2010) synthesizes predictions from social cognitive theory, the EELM, and other research on entertainment and social influence to map out how different types of involvement with entertainment fare can product different types of persuasive outcomes. Like the E-ELM, the EORM is rooted in the premise that people's motivation 
to be entertained lowers their defenses against persuasive messages. More specifically, the EORM links different types of entertainment processing to specific types of resistance reductions, including, but not limited to, reductions in psychological reactance, minimization of selective avoidance of counterattitudinal messages, reductions in counterarguing, and the lessening perceived invulnerability to issues raised by persuasive messages. For example, when people experience parasocial interaction or liking for characters, this reduces reactance to the messages these characters deliver. The experience of enjoyment reduces selective avoidance because to because it provides motivation for message exposure (even if the message is counterattitudinal). Transportation and character identification leads to a reduction in counterarguing because both processes occupy cognitive resources people would ordinarily use to argue against persuasive messages. Character identification and perceived similarity to characters reduce resistance against issues encountered by the characters in the story, because these processes encourage viewers to share the character's experiences. Taken as a whole, the EORM outlines the various ways that entertaining narratives can reduce resistance to persuasive messages.

\section{Conclusions for Narratives and Persuasion}

Taken together, these various perspectives of involvement with a narrative indicate that narratives are well-equipped to persuade individuals when they become absorbed into them. Collectively, prevailing narrative persuasion theory tends to be focused on the capacity of narratives to reduce resistance to persuasion. That is, across these explanations, reductions in counterarguing is thought to be a key mechanism of narrative persuasion; when people are fully engaged with stories, they do not muster up 
cognitive resources to generate counterarguments about points made in the narrative, about their own invulnerability, and so on, and as such, they are less likely to be aware of persuasive messages and do not want to reduce their enjoyment absorption (e.g., Dal Cin, Zanna, \& Fong, 2004; Green, 2004; Green \& Brock 2000; Hinyard \& Kreuter, 2007; Moyer-Gusé, 2008). Narratives can reduce counterarguing in several ways other ways as well (see Dal Cin, Zanna, \& Fong, 2004). Narratives can reduce biased processing because often times, persuasive messages are not as obvious when they are worked into storylines and as such, people are less likely to ignore the message or argue against it. Along the same lines, the arguments in narratives are often less obvious because they are not explicitly stated, but instead are implied as the story unfolds. In addition, the arguments that are presented in narratives can also be harder to argue against compared to rhetorical message arguments because they often relate to peoples’ experiences, which are harder to discount than overt messages.

There have been countless empirical tests of the relationship between absorption in narratives and counterarguing (e.g., Dal Cin, Zanna, \& Fong, 2004; Green, 2004; Green \& Brock 2000; Hinyard \& Kreuter, 2007; Moyer-Gusé, 2008). For example, in the first test of the transportation-imagery model, Green and Brock (2000) found that increased reports of transportation in the narrative were positively related to identifying less false notes (i.e., incorrect or faulty arguments) presented by the narrative. In another example, McQueen, Kreuter, Kalesan, and Alcaraz (2011) compared informational videos with narrative videos about breast cancer finding that engagement with the narrative decreased counterarguing, which served to influence perceptions of barriers to be tested for breast cancer and cancer fatalism in positive ways. These are just two of the 
many studies which have established a link between involvements with narratives and reduced counterarguing. Therefore, current theorizing on narrative persuasion (i.e., transportation-imagery model; engagement; E-ELM; and EORM) currently supports the belief that individuals involved with stories are more susceptible to adopting narrativeconsistent attitudes, knowledge, intentions, and so on. Aside from reduced counterarguing and engagement, there is another known mechanism - self-referencing that can also lead to persuasion.

\section{Self-Referencing}

Beyond being a product of reduced resistance to persuasion, narrative persuasion could also be a result of self-referencing. Self-referencing occurs when an individual thinks about how the self is involved with information that is presented to them in their environment; it involves their thoughts regarding their past experiences and how they relate to the information (Rogers, Kupier, \& Kirker, 1977). More specifically, Burnkrant and Unnava (1995) define self-referencing as a way of processing information where the individual relates incoming information to the self or aspects of the self. During this process, a person is reminded of their own experiences while exposed to a message and also compares this incoming knowledge to knowledge that already exists (de Graaf, 2014).

Traditionally, psychological research has identified if self-referencing has occurred by asking individuals questions regarding the content of a message and the extent to which the content makes them think about their own behaviors, by asking them to think about the personal relationship of the message to the self, and asking them to 
report on the extent to which the content reminds one of their own personal experiences (e.g., Burnkrant \& Unnava, 1989; Dunlop, Wakefield, \& Kashima, 2010).

\section{Effects of Self-Referencing on Recall and Persuasion}

The roots of self-referencing research are grounded in decades of personality and social psychology empirical work (e.g., Kupier \& Rogers, 1979; Rogers, Kupier, \& Kirker, 1977). Early studies were designed to determine whether processing information about the self leads to superior recall of information compared to processing information unrelated to the self. Kupier and Rogers (1979) compared the encoding of personal information versus others' information and found that information related to the self is more easily recalled. This finding prompted the researchers to consider the self as a type of schema. In a series of studies, they demonstrated that compared to other-referent tasks, self-referent tasks (i.e., being asked if adjectives describe the self) produced significantly greater recall of adjectives, quicker response times for recall, and more confidence in answers. They further demonstrated that self-descriptive words create strong traces in memory. Rogers, Kupier, and Kirker (1977) found similar results; their data showed that self-referencing tasks led to greater recall. They concluded that self-referencing results in effective encoding of incoming information, which sparked interest in the persuasive power of self-referencing in later research. Burnkrant and Unnava (1989) asserted that self-referencing tasks can help people to recall more of the words they have processed compared to other types of tasks because the "self is a complex, highly organized, readily accessible structure in memory” (p. 629), and that thinking about the self then provides the person with internal cues that help them retrieve words and phrases. They further assert that these internal cues should help with processing message arguments because 
there are more potential links between the information presented to the person and their own memory of their past experiences. Likewise, Kendzierski (1980) found that in comparison to situation-oriented information, self-oriented information leads to more recall. Together, these studies show a strong link between information regarding the self and later recall of that information.

Scholars have also examined the relationship between self-referencing and the elaboration of traditional, rhetorical persuasive messages operating under traditional persuasion model frameworks such as the elaboration likelihood model (ELM; Petty \& Cacioppo, 1986). Burnkrant and Unnava (1989) investigated how self-referencing might interact with message features traditionally used to induce elaboration in order to potentially impact attitudes. The researchers attempted to foster self-referent processing by asking participants to think about their own past experience with the subject in the message and by addressing participants directly (i.e., “you” vs. “one”). They also manipulated strong vs. weak arguments in their persuasive messages. Results showed that self-referencing leads to more recall of message arguments and that argument strength had a greater impact on attitudes for people in the high self-referencing condition. This result is explained by the ELM, which posits that when people find topics more personally relevant, they are more likely to elaborate on the presented messages because they want to hold correct attitudes towards issues that are important to them (Petty \& Cacioppo, 1986). As such, under elaboration stronger message arguments are perceived as more persuasive because people assign a positive valance to them. In a related series of studies, Burnkrant and Unnava (1995) further explored if the inclusion of other variables know to affect elaboration besides argument strength (i.e., the focus of their 1989 study) 
would change the positive effect self-referencing was found to have on persuasion. Study one looked at the interaction between self-referencing and picture relevance, which was the degree to which pictures presented help to depict the meaning of words. Pictures that match words with which they are presented alongside of have been show to assist people with recall due to greater elaboration from the pictures. Results of the study showed that when pictures were irrelevant, self-referencing led to increased positive attitudes towards the marketed product, but when pictures were relevant, self-referencing did not impact attitudes. This result demonstrates that when people self-reference but are not further induced to elaborate on a message, self-referencing is effective, but this effect is moderated such that adding more variables that increase elaboration will decrease the effectiveness of self-referencing on persuasion. Study two looked at the interaction between self-referencing and grammatical form of the messages, which was using questions vs. statements, because questions have been show to induce more elaboration in past research. Results demonstrated that self-referencing led to greater recall, which was also true of the questions condition. In addition, reported attitudes were more positive in the high self-reference condition for those exposed to statements and more negative for those exposed to questions. Again, these results suggest that self-referencing is effective in that it positively impacts persuasion, so long as people are not encouraged to elaborate on messages in other ways.

In another line of research, scholars have looked at tailored health communication messages, which are customized messages given to a person with the intent of making the message as relevant as possible to that person so that they adhere to the suggestions in the message (e.g., Kreuter, Bull, Clark, \& Oswald 1999; Kreuter \& Wray, 2003). This work 
has demonstrated that messages are more often perceived as relevant when they touch upon a person's life experiences or circumstances. Although not the same as selfreferencing, studies of message tailoring lend support to the idea that the recognition of the self and one's own life in a message can increase its personal relevance and persuasive potential.

More recently, Escalas (2007) has used advertisements to look at one way selfreferencing can be persuasive, which is through autobiographical memory recall, a process that distracts from weak arguments. In her study, Escalas found that when people were encouraged to imagine themselves in the setting of a print advertisement that they were shown, they reported favorable evaluations for the advertised product even in the face of weak arguments about the quality of the product. The author concluded that the preoccupation of thinking about the self in an imaginative way while confronted with this stimuli led to less scrutinizing and more positive attitudes towards a target.

\section{Self-Referencing and Narrative Persuasion}

Literary scholars have long understood that considering the self is a key ingredient of an enjoyable reading experience. Black and Seifert (1985) remarked that great literature is defined by how relatable it is and how much it reminds people of their own lives. Likewise, Abelson (1987) argued that appreciation of literature came about when readers had a personal and deep understanding of the story because it resonates with their personal experiences. According to Larsen and Seilman (1988), literature (i.e., stories) in particular is well equipped to cue this sense of "personal resonance," which is the feeling a reader has when they believe the literature is either relevant or meaningful to themselves. In a study, Larsen and Seilman asked people to mark down parts of the text 
that reminded them of themselves and immediately after reading, participants were questioned about their memories. They also compared literary text (i.e., a short-story) to expository text (i.e., an informative piece of writing). After having participants read either the literary text or the expository text, results demonstrated that the literary text led to twice as many reminding of personal experiences where people played an active role in the personal experience.

One recent study considered the relationship between self-referencing and similarity to the protagonist of a story, and how that relationship impacts persuasion. de Graaf (2014) had participants read a health narrative where the protagonist was either similar or dissimilar to participants, and measured both self-referencing and identification as potential mechanisms for the effect of perceived similarity on message effects. Results showed that those who read a story with a similar protagonist perceived more risk from intestinal cancer and reported more efficacy for dealing with the symptoms. Further, this relationship was mediated by self-referencing but not identification (i.e., taking on the perspectives and emotions of characters) demonstrating that self-referencing due to perceived similarity with characters can impact persuasive effects (e.g., story-consistent beliefs) of health narratives. de Graaf concluded that in response to narratives, perceived protagonist similarity to the individual makes it easier to relate to and connect with the experiences the protagonist goes through, which is the process of self-referencing. Consistent with research on self-referencing in response to non-narrative messages (e.g., Burnkrant \& Unnava, 1989; 1995), the greater the degree to which information is related to the self, the more likely it will be to impact peoples' attitudes and beliefs. 
Two additional studies have considered narrative structure and its relation to selfreferencing. Chen, Bell, \& Taylor (2016) compared first to third-person point-of-view narratives in terms of degree to which they cause a person to self-reference and the moderating role that protagonist similarity (i.e., age and gender) has on this relationship. Results showed that self-referencing mediated the relationship between identification, which was measured as feeling similar to, liking, feeling like, and wanting to be like the protagonist, and susceptibility. Additionally, susceptibility to and severity of experiencing a caffeine overdose predicted how persuasive the narrative was perceived to be. In a later study, the authors found that identification with the protagonist was positively related to self-referencing, self-referencing was positively related to persuasion, and identification had an indirect effect on perceived persuasiveness of a message (i.e., a proxy for persuasion in this study) through self-referencing (Chen, Bell, \& Taylor, 2017). These two studies suggest that how much a character is liked and how similar a person feels to that character can influence how susceptible that person feels to health concerns because that identification fosters references to the self, which impacts both susceptibility perceptions and perceptions of the perceived persuasiveness of messages. Taken together, these studies of narrative persuasion and self-referencing suggest that the self is a key part of narrative experiences.

\section{The Tradeoff between Narrative Engagement and Self-Referencing}

As the preceding sections should make clear, narrative engagement and selfreferencing are two mechanisms that generally increase the likelihood that people will adopt story-consistent attitudes, intentions, and so on. Stories that elicit both of these responses (i.e., engagement and self-referencing) should be more persuasive. Yet, 
theoretically speaking, these experiences should not be able to co-occur simultaneously during narrative exposure. Although measurement of engagement occurs after narrative exposure (so as not to disrupt involvement with the story), story consumers are asked to retrospectively report on their experience while they viewed or read a story. Selfreferencing is thought to occur during narrative exposure too, as evidenced by how it has been measured. Aforementioned studies of self-referencing (e.g., Chen, Bell, \& Taylor, 2016; Dunlop, Wakefield, \& Kashima, 2010) have measured self-referencing by asking participants to reflect on how much they thought about their own experiences during exposure to the narrative. Although, operationally speaking, self-referencing and engagement are both thought to occur at some point during narrative exposure, conceptually speaking, the process of self-referencing should be unable to happen at the same time as engagement. Because engagement and self-referencing have different effects on how people position themselves relative to the story, theoretically there should be tradeoff between these two processes.

In one of the only studies to consider the role of both narrative engagement and self-referencing in persuasion, Dunlop, Wakefield, and Kashima (2010) found that the experience of transportation was associated with greater reports of self-referencing. This finding seemingly contradicts the premise of this study. However, notably the researchers' measure of transportation included items that measure self-referencing (e.g., “The ad is relevant to my everyday life"). Put differently, on the face of it, the scale they used appears to have tapped into both narrative engagement related concepts (e.g., emotional engagement, presence) but also self-referencing related concepts, so it is not surprising that the study found an association between transportation and self- 
referencing. Theoretically speaking, if there is no overlap between measures of narrative engagement and self-referencing, these two processes should not be able to co-occur simultaneously.

Recall that the most prominent models of narrative involvement are all in agreement that narrative involvement involves a feeling that one is swept up in the story. During narrative transportation, Green and Brock (2000) explain that people experience a psychological loss of surroundings and reality outside of the story. Likewise, Busselle and Bilandzic (2009) describe narrative engagement as involving intense focus on the story itself without awareness that one is paying attention to the narrative.

Fundamentally, immersive narrative experiences are characterized by a lack of selfawareness. This implies that during the experience of engagement with the story, individuals should not be able to engage in self-referencing because they have psychologically moved outside of themselves. In the same manner, if people are engaged with self-referencing, this should inhibit their ability to lose themselves in the story and become immersed. If such is the case, then thinking about the self while consuming a narrative should decrease involvement with the narrative, as one is forced to think about themselves and their own reality. Therefore, the following hypotheses are put forth:

H1: Participants in the narrative engagement condition will experience less selfreferencing during narrative exposure, compared to those in the self-referencing condition.

H2: Participants in the self-referencing condition will experience less narrative engagement during narrative exposure, compared to those in the narrative engagement condition. 
H3: There will be an inverse relationship between narrative engagement and selfreferencing during narrative exposure.

Although there should be a tradeoff between these two processes, as previously discussed both are persuasively advantageous. It is not clear, however, whether one process is more persuasively effective than the other. That is, while empirical evidence for both processes demonstrate their respective persuasive potential, whether one will lead to stronger effects in story-consistent attitudes and behavioral intentions over the other is unknown. Therefore, the following research question will be explored:

RQ1: Will participants in the narrative engagement condition or the selfreferencing condition demonstrate more story-consistent (a) attitudes and (b) behavioral intentions?

\section{Self-Referencing and Counterarguing}

As previously discussed, reduced counterarguing has been shown to mediate the relationship between narrative engagement and persuasive outcomes. As an extension, reduced counterarguing may also play a role in the relationship between self-referencing and persuasive outcomes. That is, it is possible that if people are busy thinking about how the narrative events or characters relate to the self, their capacity to look for flaws in arguments may also decrease. Past research (e.g., Green \& Brock, 2000) has demonstrated that giving people a task to complete while consuming a narrative decreases their transportation, but it may also take away from their ability to counterargue. However, it is also possible that if people begin to think about themselves in relation to a health narrative, they may actually increase their counterarguing. When people encounter health risk information that they find highly relevant to the self, there is 
some evidence that they will engage in defensive strategies (McQueen, Vernon, \& Swank, 2012). One strategy that people use is counterarguing, even when they acknowledge that there is indeed some personal risk (Greenwald \& Leavitt, 1984). When they counterargue, they may refute the evidence or the source or they may minimize the harm the health threat causes. Currently, no empirical evidence about the relationship between self-referencing and counterarguing exists specifically, and because of the competing possibilities laid out here, the following research question is posed:

RQ2: Will participants in the self-referencing condition show greater or reduced counterarguing compared to participants in the narrative engagement condition?

\section{The Post-Exposure Period after Narratives and Its Persuasive Potential}

Virtually all of the explanations of why narratives are persuasive have focused on processes that occur during narrative exposure and this makes sense considering the wealth of evidence showing that online narrative consumption processes can facilitate persuasion (e.g., Busselle \& Bilandzic, 2009; Green \& Brock, 2000, Moyer-Gusé \& Nabi, 2010; \& Slater \& Rouner, 2002). However, empirical work is also beginning to accumulate on what people do after a narrative and how processes during that time can also impact persuasive outcomes.

According to some scholars, many processes that can contribute to persuasion cannot occur during narrative absorption, only after. In one line of research, examinations of post-message elaboration and character attachments demonstrate the importance of this time period for persuasion. For example, research on serious games (i.e., video games used in entertainment education programs) demonstrates that when people become involved with (i.e., absorbed in) a game and involved with characters via parasocial 
relationships, the time in between game sessions is when people reflect on what happened in the game, which is thought to affect how well the persuasive messages in the game and the entertaining parts of the game people are drawn to become intertwined (Klimmt, 2009). Developing attachments to characters in stories such as in novels or films functions in the same way in that these attachments can foster post-message elaboration. For example, Igartua and Casanova (2016) found that identification with characters of a television show predicted more post-narrative elaboration and in turn, more favorable attitudes towards several educational topics. These studies suggest that the post-exposure period may be rich with opportunities for narrative persuasion to occur or continue once the stories are completed.

There is also some research that suggests that narrative persuasion can sometimes be dependent on what happens when the story has concluded. It can be difficult to process the persuasive messages embedded in narratives until after they have finished because peoples' cognitions are deeply focused on the story itself and their cognitive capacities are reduced (e.g., Busselle \& Bilandzic, 2009; Green \& Brock, 2000), which is why the post-exposure period can be so instrumental for persuasion. In their discussion of the persuasive impact of serial entertainment-education programs, Slater and Rouner (2002) suggest that the cognitive rehearsal and social reinforcement that occurs after exposure to these programs may partially drive their effects because, as opposed to during narrative consumption, the post-exposure period gives people the opportunity to think about messages more deeply, to replay the story and its lessons in their heads, and to talk to others about the story further reinforcing its messages. Further, the authors discuss how epilogues placed at the end of these programs can shape the cognitive 
rehearsal and discussion that occurs during the post-exposure period. Lastly, it is suggested that programs with persuasive messages would benefit greatly from epilogues because otherwise, it is possible that the narrative messages have not been, "fully assimilated into audience members' belief structures” (p. 189). That is, people may need that post-exposure period to reflect on the narrative before they are fully persuaded because they may be too busy focusing on the plot and characters and trying to enjoy the story rather than analyzing its messages.

In line with the contention that story epilogues are needed to help people process persuasive messages that they would not ordinarily be able to process while they are engaged with a narrative, a handful of studies have demonstrated that exposure to postnarrative endorsements of persuasive messages enhances the influence of the stories. Moyer-Gusé, Jain, and Chung (2012) exposed participants to a narrative with an explicit appeal to avoid drinking and driving, which was related to the plot of the narrative. The purpose of putting the epilogue, as they explain, was to take time after the story was over to highlight the embedded persuasive message and also to ensure the persuasive message was clear. They found that those in the condition featuring the explicit appeal after the narrative reported significantly less favorable attitudes towards the target behavior of drinking and driving, demonstrating that utilizing the post-exposure period is more beneficial compared to not doing so.

Instead of looking at overtly persuasive epilogues, Cohen (2016) examined the effects of a "supplemental conclusion scene," a scene in which the characters in a show concluded the episode with an appeal to becoming an organ donor. Compared to those not exposed to the conclusion scene, those who did view the scene reported more 
accurate perceptions of how medical staff treat organ donors (an issue addressed in the scene). However this effect only occurred among viewers who were more motivated to find meaning in the episode. No other differences in persuasive outcomes were observed between the two conditions. The supplemental conclusion was not a true epilogue so participants may still have been transported into the narrative and unable to fully process the persuasive messages.

Finally, Cohen, Alward, Zajicek, Edwards, and Hutson (2017) showed their participants an episode of a television show with educational subtext about individuals with bipolar disorder, and showed half of their participants an epilogue featuring a public service announcement. In their results, the epilogue prompted more recognition of the persuasive subtext about bipolar disorder treatment, further demonstrating the value of the post-exposure period. Participants were more easily able to identify important persuasive subtext when they are outside of the engagement experience and can reflect back on the story messages. Taken together, these three studies examining at the postexposure period demonstrate in different ways that this time may be necessary in order to impact persuasion. While the Moyer-Gusé et al. (2012) and Cohen et al. (2017) results demonstrate usefulness of epilogues in the post-exposure period, the Cohen (2016) shows the importance of the disengagement potentially needed in order for persuasion to occur during this period.

\section{Self-Referencing in the Post-Exposure Period}

Although it has been argued here that narrative engagement and self-referencing should not be able to happen at the same time, self-referencing may still be an important determinant of narrative persuasion. Although peoples' mental faculties should be 
occupied during narrative engagement, during the post-exposure period - after narrative engagement - viewers have ample opportunity to self-reference. If given a chance to reflect back on a story once it is finished, people may naturally think about the narrative and how it relates to them on a personal level. That is, once engagement with the story has ended, people should once again have the capacity to regain self-awareness and better think about how what they were just exposed to relates themselves. If such is the case, the persuasive effects of self-referencing may come into play after all. For a viewer who has been narratively engaged, strong self-referencing would be more likely to occur after narrative consumption, rather than during. This raises the possibility that people who are narratively engaged will be able to reap the persuasive benefits of both narrative engagement and self-referencing as an after-thought. Although I have argued that narrative engagement and self-referencing cannot occur simultaneously, it is worth mentioning that Green and Brock (2000) conceptualize self-referencing as a natural component of the narrative immersion process, and it stands to reason that greater engagement during the narrative should encourage greater reflection and self-referencing after the narrative. In this way, those who are narratively engaged could, in effect, get a “double dose” of narrative influence. However, it remains to be seen just how much those who are narratively engaged will self-reference after exposure has ended. To examine this, the following research question is put forth:

RQ3: To what extent will participants in the narrative engagement condition selfreference after the narrative is over in comparison to participants in the selfreferencing condition? 


\section{CHAPTER II}

\section{Method}

\section{Participants}

Undergraduate college students $(N=223)$ were recruited from a participant pool in Communication Studies courses at a large mid-Atlantic university. Participants received extra course credit in exchange for their participation. The participants in the sample were recruited by posting hard-copies of flyers, posting digital announcements, and by making recruitment announcements in classrooms (see Appendix A for consent forms and Appendix B for recruitment materials). Participants had to be 18 years of age or older to be included in the study. After receiving approval from the Institutional Review Board at the University, data were collected during the Spring 2018 semester between March 28, 2018 and May 3, 2018.

The participants in the sample were $63.2 \%$ female, $36.8 \%$ male, and three participants did not specify their biological sex (1.3\%). The mean age of participants was 20.07 years $(S D=3.04)$. A majority of participants identified their race/ethnicity as White/Caucasian ( $n=155 ; 69.5 \%)$, followed by Middle Eastern ( $n=24 ; 10.8 \%)$, Black/African American ( $n=17 ; 7.6 \%)$, Asian/Asian America $(n=11 ; 4.9 \%)$, Other $(n=$ 10; 4.5\%), Hispanic/Latino/a ( $n=2 ; 0.4 \%)$, and those who did not specify their race/ethnicity ( $n=4 ; 1.7 \%)$.

Participants were also asked to provide information about their experiences with sex and Sexually Transmitted Infections (STIs). Of the total sample 79.8\% $(n=178)$ of participants had been sexually active at some point, $18.4 \%$ had never been sexually active $(n=41)$, and 1.8\% $(n=4)$ did not specify. Among those who reported being sexually 
active at some point, the majority had been tested for STIs ( $n=102 ; 57.3 \%)$, while a slightly smaller portion had not been tested ( $n=76 ; 42.7 \%)$.

\section{Stimulus Material}

Participants viewed episode 3 from the first season of the HBO television show Girls. The episode is titled, “All Adventurous Women Do” and originally aired on April 29, 2012. The show features multiple main characters and multiple storylines in the episode, but in the interest of participants' time, the episode was edited and shortened approximately 19 minutes to only follow the storyline that focuses on the main character, Hannah, which includes persuasive health messages.

The episode follows Hannah after she learns from her doctor that she has Human Papilloma Virus (HPV). After her diagnosis, Hannah immediately confronts and blames her current partner, Adam, for giving her HPV. In response, Adam informs her that he knows he does not have HPV because he was recently tested for it. Hannah’s friend Shoshanna tries to reassure her that she will be fine and she tells Hannah that many women who are “adventurous” have HPV including one of their close friends. Hannah later blames her former sexual partner, Elijah, for giving her HPV. Elijah tells Hannah it is not possible for her to know who gave her HPV because there is no test for men. The episode concludes with Hannah accepting her HPV-positive diagnosis by posting to social media that "All adventurous women do."

There are several lessons a viewer could take from the episode about HPV and STIs generally. Through Hannah’s journey of learning about HPV, the episode conveys a great deal of risk information about the STI including the assertion that HPV is common among sexually active individuals. Although Hannah learns about the prevalence of HPV 
and her friend convinces her that it is socially normative, she also learns that certain strains cause more serious issues like genital warts or cervical cancer. Hannah is clearly upset when she mentions her potential "pre-cancer.” She learns the importance of talking to past and current partners. Hannah also learns that men rarely develop symptoms of HPV, there is no test for HPV in men, and that it is difficult to implicate men in the spread of HPV. Most of these messages are consistent with facts distributed by the Centers for Disease Control (2017a; 2017b). However, some inaccurate information is also conveyed in the episode when Hannah's current boyfriend states that he has been tested for HPV. This misinformation is corrected before the conclusion when another character explains that men cannot be tested for HPV. In summary, the episode encourages healthy behaviors such as being tested for sexually transmitted infections and talking to all partners about an HPV diagnosis. It also encourages healthy attitudes that could function to reduce the stigma attached to an HPV diagnosis. Lastly, the episode provides accurate knowledge about HPV such as the prevalence of and potential complications from contracting HPV.

One could take away several different health messages while watching this episode, but the main message is that it is important to disclose your STI status to your past and current partners and that it is important to discuss STIs and testing with your partners generally. That is, although there are other underlying messages throughout the episode (e.g., you should not be ashamed of having HPV), the main thread of the story and the majority of the dialogue focuses on the importance of and results of discussing STIs with sexual partners. The episode focuses on multiple sexual relationships that Hannah has and follows her as she has these types of conversations with each of them. 
Although the conversations are difficult at times, Hannah learns a lot about HPV and about her partners as she discloses her STI status and attempts to maintain healthy with each of them. Therefore in the current study, attitudes towards discussing STIs and an STI diagnosis as well as behavioral intentions to have these discussions with past and current partners were selected as the persuasive outcomes of interest.

After viewing the episode in the laboratory, a majority of the participants in the sample (91.0\%) reported that they had never seen the television series Girls before the study, and most participants (95.5\%) also reported that they had never seen the specific episode of the show before they saw it in the study.

\section{Procedure}

Laboratory procedure. Prior to attending the viewing session, participants used a link for the study that brought them to a SONA website allowing them to select a date and time to come to a laboratory to take part in the study. A maximum of three participants were scheduled to come to the laboratory at one time. Upon arriving, participants were welcomed and told that they would be watching an episode of a television show followed by a few survey tasks that they would need to complete. The laboratory was equipped with three desktop computers where participants were seated, with three sets of noise-cancelling headphones. The computers were positioned in a way that did not permit participants to see the computer screens of other participants in the room. As such, participants could complete the study with confidential answers, and without knowing that they were assigned to different conditions. After an explanation of the study procedures and providing signed informed consent, participants were instructed to put on their headphones and begin the study (see Appendix E for researcher script). 
Randomization tools available on the survey website, Qualtrics, assigned participants into their respective conditions as soon as they began the online survey.

Experimental conditions. Participants were randomly assigned to one of four conditions: (1) a narrative engagement condition; (2) a self-referencing condition; (3) a mixed directions condition; or (4) a no direction condition. Appendix C displays the wording for each experimental manipulation. Participants in the narrative engagement condition read a prompt that encouraged them to engage with the story. Past studies have attempted to manipulate immersion in a story (e.g., Green, 2004; Green \& Brock, 2000) with varying degrees of success. Green and Brock (2000) successfully reduced transportation by having instructions that asked some participants to use their time to focus on finding difficult words in a text rather than immersing themselves. Green (2004) gave written instructions to participants that stated, “As we are interested in your natural responses to the passage, please try to relax and read the narrative as if you were leisurely reading a story in the comfort of your home”, but the manipulation was not successful. Participants were able to recall the instructions, but the instructions did not differentially impact transportation. Green suggested that more detailed instructions may be needed to foster transportation. As such, in the current study the instructions to participants in the engagement condition were more specific and were written to reflect closely the dimensions of narrative engagement (i.e., the dimensions proposed by Busselle \& Bilandzic, 2009). For example, the instructions asked participants to, “...only think about the story and the characters", and "If you find yourself getting distracted, renew your focus on becoming absorbed by the story”, and so on. 
Participants in the self-referencing condition read a prompt that instructed them to think about all the ways the story relates to them and their own experiences while they are watching the episode. A similar manipulation has been used and validated in past research. For example, Burnkrant and Unnava (1989; 1995) manipulated self-referencing by changing an introduction paragraph that participants read prior to exposure to the stimuli (i.e., a printed advertisement). This paragraph encouraged them to remember their own past experiences with the object shown in the advertisement (i.e., razor, 1989; calculator, 1995) as they view the ad. In both studies, the manipulation check demonstrated that those in the high self-referencing condition reported more selfreferencing and listed more thoughts that were reflective of past experiences. An example from the directions to participants in this condition in the current study is, “...try as hard as you can to connect your life and your past experiences to the story world”.

Two comparison conditions were also used in this study. The first comparison condition was a mixed directions condition where participants were given two tasks: they needed to both focus on immersing their minds into the story world (i.e., engagement directions) and to connect their personal lives and experiences to the story (i.e., selfreferencing directions). The purpose of this condition was to examine what would happen if people were encouraged to take part in both of the theoretical mechanisms for persuasion of interest in the study. I have argued that people should not be able to stay fully engaged with narratives if they are simultaneously self-referencing. If this is true, participants who are asked to do both tasks at the same time should have their overall ability to self-reference and their overall ability to engage with the narrative compromised. Participants in this mixed condition should report engaging less than those 
in the engagement condition, and they should report self-referencing less than those in the self-referencing condition. The order of which instructions came first were counterbalanced to control for order effects, such that some people in this condition were instructed to self-reference first and some were instructed to engage first.

A second no-directions comparison condition served as an experimental control. This condition that was used to determine how people naturally process a narrative in terms of engagement and self-referencing without any prompt to do one or another. This condition could also shed light on whether the experimental conditions were effective. If the instruction manipulations are ineffective, they will result in no more self-referencing or narrative engagement than what participants do when they are unprompted.

Participants in the control condition simply read a prompt that instructed them to watch the episode and they received no further instructions about what to do during exposure.

Because each of these comparison conditions served as methodological “checks” rather than inductions necessary to examine the research questions and hypotheses, Qualtrics was programmed to randomly assign only a third of the sample across one of the two comparison conditions. In total, 17\% was assigned to the mixed directions condition and $14.8 \%$ was assigned to the no directions condition. A majority - a little more than two-thirds of the sample-was randomly assigned to one of the two main experimental conditions (i.e., 34.5\% in engagement; 33.6\% in self-referencing).

Questionnaire. The online survey administered after the episode viewing consisted of two portions. The first portion examined participants' experiences during the story and the persuasive outcomes of interest. Immediately after watching the episode, all participants filled out measures for narrative engagement (Busselle \& Bilandzic, 2009), 
self-referencing (Dunlop, Wakefield, \& Kashima, 2010), and counterarguing (Nabi, Moyer-Gusé, and Byrne, 2007) to measure experiences during the narrative. These measures were counterbalanced to control for order effects. Next, participants reported on their attitudes and behavioral intentions, which are the story-consistent persuasive outcomes in the study. This group of measures was counterbalanced as well.

The second survey portion examined participants' post-exposure processing. After reporting on their experiences during viewing, participants were asked to quietly reflect on the episode for one minute and then to report all of the thoughts they had pertaining to the episode during that one minute in an open-ended format. This reflection activity permits the third research question to be addressed concerning participant's narrative processing during the post-exposure period.

Finally, the survey concluded with demographic questions and questions about participants' personal experiences with story-relevant topics, such as STIs. Because these personal questions could be distressing to some, participants were reminded that they could skip these questions if they were uncomfortable answering them. At the end of the study, participants were thanked for their time and given instructions on how to redeem the extra course credit to which they were entitled.

\section{Instrumentation}

Narrative engagement. Involvement with the story and immersion into the story was measured using an adapted version of the narrative engagement scale (Busselle \& Bilandzic, 2009), a 12-item, 7-point scale ranging from (1) Strongly Disagree to (7) Strongly Agree (see Appendix D for the survey instrument with all measures) ( $M=5.14$, $S D=.77 \alpha=.78)$. The scale is intended to capture four dimensions of engagement: 
Narrative understanding, attentional focus, narrative presence, and emotional engagement. Sample items include, “At points, I had a hard time making sense if what was going on in the program" (reverse-coded; narrative understanding); "I had a hard time keeping my mind on the program” (reverse-coded; attentional focus); "During the program, my body was in the room, but my mind was inside the world created by the story” (narrative presence); and, “The story affected me emotionally” (emotional engagement).

Self-referencing during viewing. In order to determine the degree to which the story made them think about themselves, participants filled out a four-item, 7-point selfreferencing scale ranging from (1) Strongly Disagree to (7) Strongly Agree adapted from Dunlop, Wakefield, and Kashima (2010) $(M=4.27, S D=1.56 \alpha=.87)$. Sample items include, "During my viewing of the episode, I had thoughts that this story related to me personally" and, "During my viewing of the episode, I was reminded of me and my own experiences”.

Counterarguing. Counterarguing was assessed using a four-item, 7-point scale ranging from (1) Strongly Disagree to (7) Strongly Agree adapted from Nabi, MoyerGusé, and Byrne (2007) $(M=3.59, S D=.94 \alpha=.60)$. Scale reliability was less than acceptable and item deletion did not improve the reliability of the scale. The low scale reliability strongly suggests these items do not collectively tap into the same construct. Thus, rather than treating these items as a composite of counterarguing, they were examined as four separate, single-item measures of counterarguing. These items were, "I found myself looking for flaws in the arguments made about HPV in the episode”, "I found myself actively disagreeing with the characters when they discussed HPV”, "I 
found myself actively agreeing with the arguments made in the episode about HPV” (reverse-coded), and “It was easy to agree with the arguments made about HPV in the episode” (reverse-coded).

Attitudes towards talking to partners about STI status. Participants reported their attitudes on ideas presented in the episode they watched on three-item, 7-point scales ranging from (1) Strongly Disagree to (7) Strongly Agree. These questions aimed to determine congruency between attitudes presented in the narrative and participant's attitudes. The attitude measures was that it is necessary and beneficial to talk to past and current partners after an STI diagnosis using three items $(M=6.12, S D=.98 \alpha=.65)$. Scale reliability was once again less than acceptable and item deletion did not improve the reliability of the scale. Thus, rather than treating these items as a composite of attitudes, they were examined as three separate, single-item measures of attitudes. These items were, "If I were diagnosed with an STI, it would be irresponsible of me to not talk to my past partner(s) about my diagnosis", "If I were diagnosed with an STI, it would be irresponsible of me to not talk to my current partner(s) about my diagnosis", and "If I were diagnosed with an STI, it would be good for me to talk to my partner(s)”.

Behavioral intentions to talk to partners about STI status. Participants reported on their behavioral intentions concerning having conversations with partners about STIs. On a three-item, 7-point scale ranging from (1) Extremely Unlikely to (7) Extremely Likely, participants were asked their likelihood of talking to their partners $(M=$ $5.75, S D=1.11 \alpha=.62$ ). Due to the low scale reliability and because item deletion did not improve the reliability of the scale, these items were examined as three separate, single-item measures of behavioral intentions. These items were, "If you found out that 
you have an STI, how likely would you be to tell your past sexual partner(s)", "If you found out that you have an STI, how likely would you be to tell your current sexual partner(s)", and "How likely are you to have a conversation about STIs with your partner(s) in the near future”?

Self-referencing after viewing. After filling out the close-ended measure and reflecting on the story for one minute, participants were asked to type all of the thoughts they had regarding the episode, and were instructed to contemplate any aspect of the story they would like. The survey then instructed participants to write one thought per textbox available to them, and they were permitted to enter anywhere from 1-10 thoughts. On the next page, participants were then asked to identify or code their own reflections. The thoughts participants recorded were individually displayed again, and they were asked to indicate whether each thought was related to themselves or their own experiences in a yes or no format. For the thoughts that they indicate were about the self, the survey software automatically provided them with a space and an open-ended prompt instructing them to elaborate further on how or why the thought was related to the self. Having participants self-describe why they identified certain thoughts as instances of self-referencing was intended to assist in determining whether or not they had correctly listed self-related thoughts or not.

These thoughts were later coded by the researcher to check if the thoughts were actually self-related thoughts. In order to verify that participants' self-identified reports of self-referencing were, in fact, instances of self-referencing and so that the number of selfreferencing thoughts each participant reported could be tabulated, the researcher and a trained coder content analyzed each individual thought. Self-referencing was considered 
any thoughts about the self that were related to past or present experiences, aspects of the self, or knowledge already or not already possessed. Thoughts that did not count as selfreferencing included emotional reactions to the story, opinions, preferences, and generalized statements about others (e.g., "everyone should do this behavior”) (see Appendix F for the codebook used in this analysis). This analysis permitted a calculation of the number of self-referencing thoughts each participant reported. The coders independently reviewed thoughts that were self-identified by participants as being selfreferencing. Those instances that matched the conceptualization of self-referencing in the codebook were coded as 1 , and those that did not were coded as 0 . If participants indicated a thought was not about themselves, these thoughts were also coded as not selfreferencing, or 0 . In total, there were 2,230 cases that needed to be coded across the 223 participants including thought-spaces participants left blank. In 2,168 cases, the coders agreed as to whether the thoughts constituted self-referencing or not, and in 62 cases the coders disagreed. The inter-coder reliability was then computed showing a rate of agreement of 97.22\%, and their reliability was good (Scott's pi = .91; Krippendorff's alpha $=.91)$. To resolve disagreements, the coders discussed their decisions with each other until consensus was reached. Following coding, the total number of self-referencing thoughts for each participant was calculated from the sum of all thoughts coded as 1 across each participant. In total, participants indicated that they had a self-referencing thought 562 times. Out of these times, there were 158 instances (28.1\%) where participants' thoughts were not actually self-referencing as conceptualized for this project. As such, there was a total of 404 confirmed instances of self-referencing thoughts $(M=1.81, S D=1.79)$. 


\section{CHAPTER III}

\section{Results}

\section{Descriptive and Preliminary Analyses}

Table 1 displays the zero-order correlations between the variables of interest in this study. These analyses show that compared to males in this sample, females engaged more with the story $(r=.23, p=.001)$, self-referenced during the narrative more $(r=17$, $p=.01)$, and counterargued less $(r=-.16, p=.02)$. In terms of persuasion-related outcomes, compared to males in the sample, females reported more positive attitudes towards talking to their partners about testing $(r=.15, p=.03)$.

Each of the during-narrative variables were significantly related to each other and to many of the persuasion-related outcomes. Engagement with the narrative was positively related to self-referencing during the story $(r=.43, p>.001)$ and negatively related to counterarguing $(r=-.33, p<.001)$. Engagement was also positively related to attitudes towards talking to partners about an STI diagnosis $(r=.29, p,<.001)$ and intentions to talk to partners about STIs $(r=.15, p=.03)$. Engagement was also positively related to the amount of post-exposure self-referencing $(r=.24, p>.001)$.

Self-referencing during the narrative was negatively related to counterarguing $(r=$ $-.21, p=.002)$. For the persuasion-related outcomes, self-referencing during the story was positively related to attitudes towards talking to partners about an STI diagnosis $(r=.23$, $p<.001)$ and intentions to talk to partners about STIs $(r=.17, p=.01)$. Self-referencing during the narrative was also positively related to self-referencing after the narrative $(r=$ $.35, p<.001)$. 
Table 1

Zero-Order Correlation Matrix

\begin{tabular}{|c|c|c|c|c|c|c|c|c|}
\hline Variables & 1 & 2 & 3 & 4 & 5 & 6 & 7 & 8 \\
\hline \multicolumn{9}{|l|}{ Demographics } \\
\hline 1. Biological Sex & - & & & & & & & \\
\hline 2. Sexually Active & .07 & - & & & & & & \\
\hline 3. Past STI Testing & $.23 * *$ & $.45^{* *}$ & - & & & & & \\
\hline \multicolumn{9}{|l|}{$\begin{array}{l}\text { During-Narrative } \\
\text { Variables }\end{array}$} \\
\hline 4. Engagement & $.23 * *$ & .06 & .12 & - & & & & \\
\hline 5. Self-Referencing & $.17^{*}$ & $.24 * *$ & $.26^{* *}$ & $.43^{* *}$ & - & & & \\
\hline 6. Counterarguing & $-.16^{*}$ & $-.15^{*}$ & -.13 & $-.33 * *$ & $-.21^{* *}$ & - & & \\
\hline \multicolumn{9}{|l|}{$\begin{array}{l}\text { Persuasion-Related } \\
\text { Outcomes }\end{array}$} \\
\hline $\begin{array}{l}\text { 7. STI Disclosure } \\
\text { Attitudes }\end{array}$ & $.15^{*}$ & $.16^{*}$ & $.16^{*}$ & $.29 * *$ & $.23^{* *}$ & $-.22 * *$ & - & \\
\hline $\begin{array}{l}\text { 8. Intentions to } \\
\text { Talk About STIs }\end{array}$ & .11 & .13 & $.19^{* *}$ & $.15^{*}$ & $.17^{*}$ & $-.15^{*}$ & $.49 * *$ & - \\
\hline $\begin{array}{l}\text { Post-Exposure } \\
\text { Outcome }\end{array}$ & & & & & & & & \\
\hline
\end{tabular}

$\begin{array}{lllllllll}\text { 9. Self-Referencing } & .13 & .14^{*} & .08 & .24 * * & .35^{* *} & -.20^{* *} & .22^{* *} & .21^{* *} \\ \text { After }\end{array}$ Note. ${ }^{*} p \leq 05 .{ }^{* *} p \leq .001$. Biological sex is coded as $0=$ male, $1=$ female. Sexually active and tested for STIs are coded as $0=$ no, $1=$ yes.

Counterarguing was negatively related to attitudes towards talking to partners about an STI diagnosis $(r=-.22, p=.001)$, intentions to talk to partners about STIs $(r=-$ $.15, p=.03)$, and self-referencing after the narrative $(r=-.20, p=.003)$.

The two persuasion-related outcomes were related to each other as well. Attitudes towards talking to partners about an STI diagnosis was positively related to intentions to talk to partners about STIs $(r=.49, p<.001)$. 
Finally, both persuasion outcomes were related to self-referencing after the narrative (attitudes, $r=.22, p=.001$; intentions, $r=.21, p=.002$ ).

Given the significant relationship between biological sex and the dependent variables measuring processes during the narrative seen in the zero-order correlations, and given its relationship to many of the persuasion-related dependent variables, this variable was entered as a covariate in all of the subsequent reported analyses. Similarly, having ever been sexually active as well as an experience with Sexually Transmitted Infections (STISs) variable (i.e., past testing for STIs) were also related to many of the dependent variables and they were also entered as covariates in all of the analyses in the study.

Manipulation checks. In order to examine how well participants understood the instruction manipulations they were given in their respective conditions, two verifications were put in place in the survey. In the first check, which occurred directly after reading the manipulation instructions, participants were asked to report what task they were supposed to do while watching the episode in an open-ended format. In the second check, which occurred later in the survey just after the persuasion outcomes were measured, participants were given four multiple choice options and asked to identify the instructions that they had been given prior to watching the episode (i.e., engage, self-reference, both, or just watch the show).

The open-ended responses to the first check were coded by the researcher and a trained coder (see Appendix F for the codebook used in this analysis). The coders independently read each participants' response and coded the response as either being in one of the four experimental conditions or in a fifth category for when the coders could 
not determine what condition the person may have been in. In total there were 223 responses that were coded where the coders agreed on 192 cases and disagreed on 31 cases. The inter-coder reliability was computed showing a rate of agreement of $86.10 \%$ with an acceptable reliability (Scott's pi $=.80$; Krippendorff's alpha $=.80$ ). Differences in coding were again discussed between the coders until consensus was reached. The multiple-choice check was coded according to whether participants correctly identified the instructions condition they had been randomly assigned to. In total, 57 participants (25.6\% of the sample) did not accurately describe the instructions they were given in the open-ended check and 60 participants (26.9\%) failed to correctly identify the instructions they were given in the multiple choice item.

The high proportion of participants who failed at least one of the manipulation checks suggests that the instructions manipulations were not successful. However, it bears note that there was not a great amount of overlap between those who failed the first check and those who failed the second. In other words, several participants who were unable to articulate the instructions they were given in their own words, were nonetheless able to identify the instructions they were given correctly. Likewise, several individuals who incorrectly identified the instructions later in the survey had already successfully described the instructions in their own words. In fact, only 24 participants $(10.8 \%$ of the sample) failed both manipulation checks. Although the instructions may have been misunderstood (i.e., the manipulations failed and participants were unable to follow the instructions), the high percentage of respondents who correctly responded to at least one of the checks, suggests the possibility that participants were confused by the manipulation check questions rather than the manipulations themselves. Nonetheless, 
because failing both manipulation checks would, at the least indicate that a participant was not properly attending to study, the respondents who were unable to answer these two questions correctly were initially excluded from the analyses. Because this omission did not affect the pattern of any results however, it was decided that these participants likely did not have a markedly unique experience in the study that would preclude their inclusion. Henceforth, all reported analyses are conducted using the complete sample.

Comparison Condition Analyses. In order to determine what effects, if any, the experimental instructions had on engagement and self-referencing compared to the effects of viewing naturally (without any instructions) or trying to perform both sets of instructions during viewing, differences between the four conditions (two comparison conditions and two experimental conditions) were explored as part of the preliminary analyses. A multiple analysis of covariance (MANCOVA) was conducted with biological sex, sexual activity status, and past STI testing behaviors entered as covariates. These three covariates were included because they are correlated with the narrative engagement and self-referencing. Results of the MANCOVA showed that at least one of the two dependent variables did differ across instruction conditions (Wilks' $\lambda=.91, F(6,418)=$ $\left.3.55, p=.002, \eta_{\mathrm{p}}{ }^{2}=.05\right)$. Specifically, there was a significant difference between the amount of self-referencing viewers engaged in between the conditions $(F(3,210)=5.07$, $\left.p=.002, \eta_{\mathrm{p}}^{2}=.07\right)$ although the effect size was relatively small. However, there were no differences in the amount of narrative engagement experienced in the four conditions $\left(F(3,210)=1.41, p=.24, \eta_{\mathrm{p}}^{2}=.02\right)$. The mean levels of viewer narrative engagement across the four conditions is displayed in Table 2. This finding indicates that the narrative engagement manipulation was unsuccessful at eliciting story immersion. Regardless of 
whether participants were instructed to engage with the narrative, self-reference, or do nothing in particular, they reported similar levels of narrative engagement.

Table 2

Means, Standard Deviations, and Pairwise Comparisons of Narrative Engagement between the Experimental and Comparison Conditions

\begin{tabular}{|c|c|c|c|c|c|c|c|c|}
\hline \multirow[b]{2}{*}{ Condition } & \multirow[b]{2}{*}{ Madj } & \multirow[b]{2}{*}{$S D$} & \multirow[b]{2}{*}{ (I) } & \multirow[b]{2}{*}{$(\mathrm{J})$} & \multirow[b]{2}{*}{$\begin{array}{l}\text { Mean Diff. } \\
\text { (I-J) }\end{array}$} & \multirow[b]{2}{*}{$S E$} & \multicolumn{2}{|c|}{$\begin{array}{c}\text { 95\% Confidence } \\
\text { Interval } \\
\end{array}$} \\
\hline & & & & & & & $\begin{array}{l}\text { Lower } \\
\text { Bound }\end{array}$ & $\begin{array}{l}\text { Upper } \\
\text { Bound } \\
\end{array}$ \\
\hline $\mathrm{NE}$ & 5.19 & .78 & $\mathrm{NE}$ & SR & .12 & .13 & -.21 & .46 \\
\hline SR & 5.07 & .78 & & MD & -.13 & .15 & -.54 & .27 \\
\hline MD & 5.32 & .76 & & ND & .19 & .16 & -.23 & .61 \\
\hline \multirow[t]{3}{*}{ ND } & 5.00 & .76 & SR & MD & -.26 & .15 & -.66 & .15 \\
\hline & & & & ND & .06 & .16 & -.36 & .49 \\
\hline & & & MD & ND & .32 & .18 & -.16 & .80 \\
\hline
\end{tabular}

Note. Table shows results from a MANCOVA where mean differences have been adjusted. NE = Narrative Engagement; SR = Self-Referencing; MD = Mixed Directions; ND = No Directions.

A multiple comparison analysis with a Bonferroni correction was conducted to determine which conditions elicited differences in the amount of reported self-referencing during viewing. Table 3 displays the mean differences between conditions. These comparisons revealed that those who were instructed to self-reference reported engaging in more self-referencing during the narrative $\left(M_{\mathrm{adj}}=4.65, S D=1.50\right)$ compared to those who were not given any instructions $\left(M_{\mathrm{adj}}=3.65, S D=1.54\right)$. Additionally, those in the mixed instructions condition who were told to both engage with the narrative and to selfreference reported more self-referencing during the narrative $\left(M_{\text {adj }}=4.62, S D=1.59\right)$ compared to those who were not given any instructions $\left(M_{\mathrm{adj}}=3.65, S D=1.54\right)$. These 
results strongly suggest that the self-referencing manipulation used in this study was successful, as participants in both of the conditions in which they were instructed to selfreference (the self-referencing condition and the mixed instructions condition) engaged in more self-referencing compared to those who were not given any particular instructions.

Table 3

Means, Standard Deviations, and Pairwise Comparisons of Self-Referencing between the Experimental and Comparison Conditions

\begin{tabular}{|c|c|c|c|c|c|c|c|c|}
\hline \multirow[b]{2}{*}{ Condition } & \multirow[b]{2}{*}{ Madj } & \multirow[b]{2}{*}{$S D$} & \multirow[b]{2}{*}{ (I) } & \multirow[b]{2}{*}{$(\mathrm{J})$} & \multirow[b]{2}{*}{$\begin{array}{l}\text { Mean Diff. } \\
\text { (I-J) }\end{array}$} & \multirow[b]{2}{*}{$S E$} & \multicolumn{2}{|c|}{$\begin{array}{l}\text { 95\% Confidence } \\
\text { Interval }\end{array}$} \\
\hline & & & & & & & $\begin{array}{l}\text { Lower } \\
\text { Bound }\end{array}$ & $\begin{array}{l}\text { Upper } \\
\text { Bound }\end{array}$ \\
\hline $\mathrm{NE}$ & 4.06 & 1.44 & $\mathrm{NE}$ & SR & -.58 & .24 & -1.21 & .04 \\
\hline SR & 4.65 & 4.50 & & MD & -.56 & .29 & -1.32 & .20 \\
\hline MD & 4.62 & 1.59 & & ND & .42 & .30 & -.38 & 1.21 \\
\hline \multirow[t]{3}{*}{ ND } & 3.65 & 1.54 & SR & MD & .03 & .30 & -.74 & .79 \\
\hline & & & & ND & $1.00 *$ & .29 & .20 & 1.80 \\
\hline & & & MD & ND & $.98 *$ & .34 & .07 & 1.88 \\
\hline
\end{tabular}

Note. Table shows results from a MANCOVA where mean differences have been adjusted. * denotes mean differences significant at the $\mathrm{p}<.05$ level. $\mathrm{NE}=$ Narrative Engagement; $\mathrm{SR}=$ SelfReferencing; $\mathrm{MD}=$ Mixed Directions; ND = No Directions.

\section{Hypothesis Tests}

Because none of the proposed hypotheses or research questions required the inclusion of the two comparison conditions in the study, the remainder of analyses excluded participants who were assigned to these conditions. That is, only the two experimental conditions (i.e., narrative engagement and self-referencing) were compared to formally test the hypotheses and research questions, leaving 152 participants in the remaining analyses. 
Hypothesis 1 predicted that engagement with the narrative would result in less self-referencing during narrative exposure. Hypothesis 2 predicted self-referencing would result in less narrative engagement. Finally, the second research question aimed to determine whether self-referencing or narrative engagement would result in greater amounts of counterarguing. To investigate H1, H2, and RQ2, a MANCOVA was performed with the two experimental conditions entered as independent variables, and narrative engagement, self-referencing, and counterarguing during the episode entered as dependent variables. Because the counterarguing scale exhibited low reliability, instead of looking at the scale's four items as a composite, they were instead entered as four distinct dependent variables. Once again, because biological sex, sexual activity status, and past STI testing were correlated with the dependent variables, they were entered as covariates. Results of this analysis revealed no differences in the dependent variables between the experimental conditions in the overall multivariate model (Wilks' $\lambda=.92$, $F(6,136)=1.98, p=.07)$. However, self-referencing did differ significantly between conditions $\left.F(1,141)=5.71, p=.02, \eta_{\mathrm{p}}^{2}=.04\right)$, although the effect size was small. Uncovering support for $\mathrm{H} 1$, a pairwise comparison revealed that those in the selfreferencing condition reported significantly greater self-referencing $\left(M_{\mathrm{adj}}=4.63, S D=\right.$ 1.50) than those in the engagement condition $\left(M_{\mathrm{adj}}=4.08, S D=1.44\right), I-J=.55, p=$ .02 .

In sum, participants in the self-referencing condition did engage in more selfreferencing than those in the narrative engagement condition, however, being instructed to self-reference did not affect how narratively engaged these viewers were. There were 
no differences in narrative engagement or in any of the counterarguing indicators between the two experimental conditions.

Hypothesis 3 predicted an inverse relationship between narrative engagement and self-referencing. A Pearson product-moment correlation coefficient was computed to assess this relationship, demonstrating a positive relationship between the two variables $(r=.43, p>.001)$ contrary to the prediction. Therefore, hypothesis 3 was not supported.

The first research question inquired as to whether instructions to focus on narrative engagement or self-referencing during the narrative lead to any differences in persuasion-related outcomes. A MANCOVA was performed to examine differences between the two conditions on various persuasion-related outcomes. Attitudes towards talking to partners about STI disclosure and behavioral intentions to talk to partners about STIs were entered as the dependent variables. Due to the low reliability of the attitudes towards talking to partners about an STI diagnosis scale, the three items that made up the original scale were entered as three separate dependent variables. Likewise, due to the low reliability of the intentions to talk to partners about an STI diagnosis and STIs scale, the three items of the scale were entered as three additional dependent variable. Biological sex, sexual activity status, and past STI testing behavior were again entered into the model as covariates. The analysis did not reveal any differences between the narrative engagement and the self-referencing conditions in terms of these persuasionrelated outcomes (Wilks' $\lambda=.97, F(6,125)=.69, p=.66)$.

Finally, the third research question asked about the extent to which people would self-reference after the narrative was over in the post-exposure period, and whether postnarrative self-referencing would differ between those in the engagement and self- 
referencing conditions. An ANCOVA was performed to compare the two conditions on the amount of thoughts participants in each had in the post-exposure time period. Descriptive statistics showed that the data for number of self-referencing thoughts after the episode were not normally distributed $(M=1.81, S D=1.79$, Skewness $=1.31)$ and therefore, the data were transformed with a square root function to account for distribution’s non-normality. Once again, biological sex, sexual activity status, and past STI testing were included as covariates. Additionally, the degree that participants selfreferenced during the narrative was also controlled for in this analysis to isolate the postexposure period from what occurred during narrative exposure. The results did not reveal any differences between the two conditions $\left(F(1,141)=.02, p=.88, \eta_{\mathrm{p}}^{2}<.001\right)$. Regardless of what people focus on while consuming narratives, they appear to engage in the same amount of self-referencing after the narrative is over once they have had time to reflect.

\section{Supplemental Analysis}

Although the narrative engagement manipulation failed and therefore this study cannot draw conclusions about the effects of induced narrative engagement, it is still possible to examine the dynamics between the narrative engagement that occurred naturally across conditions and the other variables of interest. Understanding more about how narrative engagement interacts with self-referencing is of particular importance.

As previously discussed, research has found that independently, both narrative engagement and self-referencing have a positive impact on persuasion (Burnkrant \& Unnava, 1995; Green \& Brock, 2000). Further, this study demonstrates that not only do increases in self-referencing not interfere with narrative engagement, these two variables 
are actually positively correlated. This suggests that these two processes could work together during narrative exposure to enhance persuasion. To examine this possibility, a supplemental analysis was conducted to investigate self-referencing as a moderator of narrative engagement's effects on persuasion using the full sample $(N=223)$.

A series of Ordinary Least Squares hierarchical regression analyses were performed. Experimental condition, biological sex, sexual activity status, and past STI testing behavior were entered as covariates in the first step of the models. The second step consisted of narrative engagement and self-referencing. A self-referencing and narrative engagement interaction term was entered as the third step. Each of the six models were identical except they had different dependent variables: one of the three indicators of attitudes towards disclosing STI status to partners or one of the three indicators of behavioral intentions to talk to partners about STIs.

The first analysis examined positive attitudes towards talking to past partners about STI status as the dependent variable. This model accounted for $12 \%$ of the variance in the dependent variable, $R^{2}=.12, F(7,205)=3.95, p<.001$. Results of the analysis are displayed in Table 4. Sexual activity status and being narratively engaged were the only significant predictors of attitudes towards talking to past partners. Being sexually active $(b=.68, p=.01)$ and more narratively engaged $(b=.42, p=.001)$ were both associated with more positive attitudes towards disclosing their own STI status to their past partners. 
Table 4

Hierarchical Regression Predicting Positive Attitudes towards Talking to Past Partners about STI Status

\begin{tabular}{|c|c|c|c|c|}
\hline & $b$ & $S E$ & $\beta$ & $\Delta R^{2}$ \\
\hline \multicolumn{5}{|l|}{ Controls } \\
\hline Biological Sex $(0$ = male $)$ & .07 & .19 & .03 & .06 \\
\hline Sexual Activity Status ( $0=$ not active $)$ & $.68 * *$ & .25 & .20 & \\
\hline Past STI Testing $(0=$ not tested $)$ & .06 & .20 & .02 & \\
\hline Experimental Condition ( 0 = no instructions) & -.32 & .25 & -.09 & \\
\hline \multicolumn{4}{|l|}{ Narrative Processing } & .06 \\
\hline Narrative Engagement & $.42 * * *$ & .13 & .25 & \\
\hline Self-Referencing & .01 & .07 & .02 & \\
\hline \multirow{3}{*}{$\begin{array}{l}\text { Interaction } \\
\text { Narrative Engagement x Self Referencing }\end{array}$} & & & & .001 \\
\hline & -.04 & .07 & -.27 & \\
\hline & \multicolumn{4}{|c|}{$\begin{array}{c}R^{2}=.12 \\
, 205)=3.95, p<.001\end{array}$} \\
\hline
\end{tabular}

Note. $b$ in the table is an unstandardized regression coefficients at entry and $\underline{\beta}$ 's are standardized coefficients at entry.

Positive attitudes towards talking to current partners about STI status was entered as the dependent variable in the next model. The findings of this analysis are illustrated in Table 5 . The model accounted for $10 \%$ of the variance in the dependent variable, $R^{2}=$ $.10, F(7,202)=3.16, p=.003)$. In this case, narrative engagement was the only significant predictor $(b=.30, p=.04)$ of attitudes towards discussion with current partners about one’s STI status such that engagement was associated with increased positive attitudes. 
Table 5

Hierarchical Regression Predicting Positive Attitudes towards Talking to Current Partners about STI Status

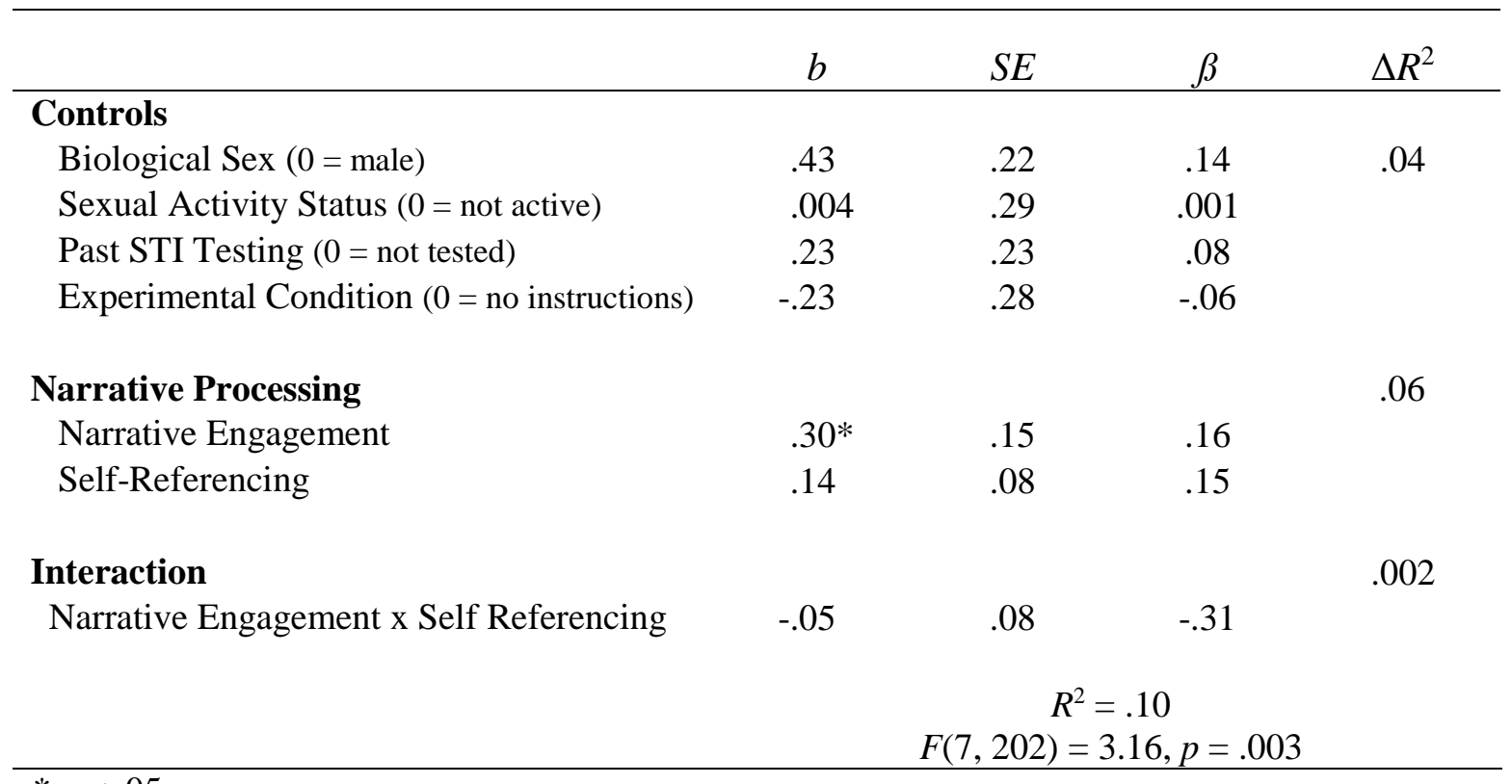

$* p<.05$

Note. $b$ in the table is an unstandardized regression coefficients at entry and $\underline{\beta}$ 's are standardized coefficients at entry.

In the final analysis that examined attitudes as outcomes, positive attitudes towards talking to partners about STI status in general, the model accounted for $9 \%$ of the variance in the dependent variable $\left.R^{2}=.09, F(7,202)=2.91, p=.01\right)$. Receiving instructions on what to focus on during the video was the only significant predictor $(b=$ $.45, p=.02)$ such that compared to those who did not receive any instructions on what to focus on during viewing, those who did receive instructions had less positive attitudes towards talking to partners about STI status. 
Table 6

Hierarchical Regression Predicting Positive Attitudes towards Talking to Partners about STI Status in General

\begin{tabular}{|c|c|c|c|c|}
\hline & $b$ & SE & $\beta$ & $\Delta R^{2}$ \\
\hline \multicolumn{5}{|l|}{ Controls } \\
\hline Biological Sex $(0=$ male $)$ & .22 & .15 & .10 & .07 \\
\hline Sexual Activity Status ( $0=$ not active $)$ & .31 & .21 & .11 & \\
\hline Past STI Testing $(0=$ not tested $)$ & .15 & .16 & .07 & \\
\hline Experimental Condition ( $0=$ no instructions $)$ & $-.45 *$ & -.15 & -.15 & \\
\hline \multicolumn{4}{|l|}{ Narrative Processing } & .02 \\
\hline Narrative Engagement & .19 & .11 & .14 & \\
\hline Self-Referencing & .02 & .06 & .02 & \\
\hline \multirow{3}{*}{$\begin{array}{l}\text { Interaction } \\
\text { Narrative Engagement x Self Referencing }\end{array}$} & & & & .003 \\
\hline & -.04 & .06 & -.40 & \\
\hline & \multicolumn{4}{|c|}{$\begin{array}{c}R^{2}=.09 \\
F(7 \quad 202)=291 \quad n\end{array}$} \\
\hline
\end{tabular}

$* p<.05$

Note. $b$ in the table is an unstandardized regression coefficients at entry and $\underline{\beta}$ 's are standardized coefficients at entry.

A series of analyses were also conducted to examine the effects of narrative engagement and self-referencing on viewers' behavioral intentions. In the first of these analyses, the independent variables were regressed on intentions to disclose STI status to past partners. The results of this analysis are displayed in Table 7 . The overall model was not significant and none of the independent variables predicted intentions to talk to past partners about STI status. 
Table 7

Hierarchical Regression Predicting Intentions to Disclose STI Status to Past Partners

\begin{tabular}{|c|c|c|c|c|}
\hline & $b$ & $S E$ & $\beta$ & $\Delta R^{2}$ \\
\hline \multicolumn{5}{|l|}{ Controls } \\
\hline Biological Sex $(0$ = male $)$ & -.11 & .22 & -.04 & .02 \\
\hline Sexual Activity Status $(0=$ not active $)$ & .38 & .30 & .10 & \\
\hline Past STI Testing $(0=$ not tested $)$ & -.06 & .24 & -.02 & \\
\hline Experimental Condition ( $0=$ no instructions) & -.42 & .29 & -.12 & \\
\hline \multicolumn{2}{|l|}{ Narrative Processing } & & & .02 \\
\hline Narrative Engagement & .25 & .15 & .13 & \\
\hline Self-Referencing & .04 & .08 & .04 & \\
\hline \multicolumn{4}{|l|}{ Interaction } & .01 \\
\hline \multirow[t]{2}{*}{ Narrative Engagement x Self Referencing } & -.12 & .08 & -.79 & \\
\hline & \multicolumn{4}{|c|}{$\begin{array}{c}R^{2}=.05 \\
F(7,197)=1.56, p=.15\end{array}$} \\
\hline
\end{tabular}

Note. $b$ in the table is an unstandardized regression coefficients at entry and $\underline{\beta}$ 's are standardized coefficients at entry.

Next, intentions to disclose STI status to current partners entered as the dependent variable. Table 8 displays the results of this model, which accounts for $9 \%$ of the variance in the dependent variable, $\left.R^{2}=.09, F(7,197)=2.85, p=.01\right)$. In this model, sexual activity status was a significant predictor of intentions to talk to current partners about STI status $(b=.50, p=.02)$, such that those who were sexually active at some point in their lives were more likely to talk to their current partners. 
Table 8

Hierarchical Regression Predicting Intentions to Disclose STI Status to Current Partners

\begin{tabular}{|c|c|c|c|c|}
\hline & $b$ & $S E$ & $\beta$ & $\Delta R^{2}$ \\
\hline \multicolumn{5}{|l|}{ Controls } \\
\hline Biological Sex (0 = male) & .10 & .16 & .04 & .06 \\
\hline Sexual Activity Status $(0=$ not active $)$ & $.50 *$ & .22 & .18 & \\
\hline Past STI Testing $(0=$ not tested $)$ & .12 & .17 & .06 & \\
\hline Experimental Condition ( $0=$ no instructions) & -.36 & .21 & -.12 & \\
\hline Narrative Processing & & & & .03 \\
\hline Narrative Engagement & .20 & .11 & .14 & \\
\hline Self-Referencing & .03 & .06 & .05 & \\
\hline Interaction & & & & .002 \\
\hline \multirow[t]{2}{*}{ Narrative Engagement x Self Referencing } & -.04 & .06 & -.32 & \\
\hline & \multicolumn{4}{|c|}{$\begin{array}{c}R^{2}=.09 \\
F(7,197)=2.85, p=.01\end{array}$} \\
\hline
\end{tabular}

Note. $b$ in the table is an unstandardized regression coefficients at entry and $\underline{\beta}$ 's are standardized coefficients at entry.

Finally, intentions to discuss STIs in general with partners was also examined as an outcome. These results are illustrated in Table 9. The model accounted for $11 \%$ of the variance in the dependent variable, $\left.R^{2}=.11, F(7,196)=3.47, p=.002\right)$. In this case, past STI testing and experimental condition predicted intentions to discuss STIs with partners such that those who were tested were more likely to talk to their partners about STIs in general ( $b=.87, p=.002)$ and receiving any instructions (vs. no instructions at all) decreased how likely participants were to talk $(b=-.71, p=.03)$. 
Table 9

Hierarchical Regression Predicting Intentions to Talk to Partners about STIs in General

\begin{tabular}{|c|c|c|c|c|}
\hline & $b$ & $S E$ & $\beta$ & $\Delta R^{2}$ \\
\hline \multicolumn{5}{|l|}{ Controls } \\
\hline Biological Sex $(0$ = male $)$ & .28 & .26 & .07 & .09 \\
\hline Sexual Activity Status ( $0=$ not active $)$ & -.40 & .35 & -.09 & \\
\hline Past STI Testing $(0=$ not tested $)$ & $.87 * *$ & .27 & .25 & \\
\hline Experimental Condition ( 0 = no instructions) & $-.71 *$ & .33 & -.15 & \\
\hline \multicolumn{2}{|l|}{ Narrative Processing } & & & .02 \\
\hline Narrative Engagement & .04 & .17 & .02 & \\
\hline Self-Referencing & .15 & .09 & .13 & \\
\hline \multicolumn{2}{|l|}{ Interaction } & & & .001 \\
\hline \multirow[t]{2}{*}{ Narrative Engagement x Self Referencing } & -.04 & .09 & -.21 & \\
\hline & \multicolumn{4}{|c|}{$\begin{array}{c}R^{2}=.11 \\
F(7,196)=3.47, p=.002\end{array}$} \\
\hline
\end{tabular}

Note. $b$ in the table is an unstandardized regression coefficients at entry and $\underline{\beta}$ 's are standardized coefficients at entry.

In summary, these analyses demonstrate that only narrative engagement had any effect on the persuasive outcomes of interest. Specifically, greater narrative engagement was associated with more positive attitudes towards discussing STI status with past and current partners, even when controlling for factors such as participants' sexual activity status and past experience with STI testing. However notably, narrative engagement did not have any significant effect on any behavioral intentions. Self-referencing affected neither viewers' attitudes nor behavioral intentions. Further, self-referencing did not interact with narrative engagement to affect any persuasive outcome. 


\section{CHAPTER IV}

\section{Discussion}

The current collection of findings from research regarding stories and their persuasive potential demonstrates that narratives can be used as a means of persuading individuals to adopt healthy attitudes, behaviors, and the like (e.g., Busselle \& Bilandzic, 2009; Green and Brock, 2000, 2002; Moyer-Gusé \& Nabi, 2010; Slater \& Rouner, 2002). Many mechanisms have been proposed and tested as responsible for the story-consistent persuasive outcomes that result from narrative exposure, including reduced counterarguing (Slater \& Rouner, 2002), emotional connections to characters and storylines (Green \& Brock, 2000), perspective-taking through identification with characters (Cohen, 2001), and intense comprehension of and presence in the story world allowing persuasion attempts to remain unnoticed (Busselle \& Bilandzic, 2009). All of these mechanisms—related to the narrative itself—have been shown to influence narrative persuasion in meaningful ways.

There are several gaps in our understanding about how processes that are more external or tangential to the story and more closely related to the self affect narrative persuasion, however. Research has repeatedly suggested that narrative engagement is a process that suppresses viewers' ability to process things other than the narrative, such as considering arguments against the persuasive subtext (e.g., Busselle \& Bilandzic, 2009; Green \& Brock, 2000). Like counterarguing, self-referencing is a process that requires focus be directed somewhat outside of the narrative events. The unique role that this process might play in the narrative engagement process had not been examined. Another gap in narrative persuasion research is an understanding of how self-referencing affects persuasive outcomes in response to narratives. The process of self-referencing, a well- 
established route to non-narrative persuasion (Burnkrant \& Unnava, 1995; Kupier \& Rogers, 1979), was assumed to play an influential role in how stories persuade, but this had not been formally tested or confirmed. Finally, the vast amount of narrative persuasion research has concerned itself with processes that facilitate persuasion during narrative consumption. Generally speaking, processes that may occur after a story concludes have been largely unexplored with some notable exceptions (e.g., Cohen, 2016; Cohen et al., 2017; Moyer-Gusé et al., 2012), even though there is some reason to suspect that narrative persuasion outcomes may have as much to do with how people engage with a story after they are finished with the story (e.g., Nabi \& Green, 2016; Slater \& Rouner, 2002). It was proposed here that there may be differences in the degree that people self-reference after a story based on the way they processed the story because what process they were engaged in during the story (i.e., narrative engagement or selfreferencing) could impact what they thought about after the story.

This study begins filling in the aforementioned gaps in the narrative persuasion and self-referencing literature. The contention that narrative engagement and selfreferencing in response to narratives cannot simultaneously co-occur because they demand different levels of immersion in the story was tested. This study did not uncover any indication that these two persuasive processes are mutually exclusive. There was no evidence of there being a tradeoff between engaging in self-referencing and narrative engagement. Although counterarguing is the only cognitive process that has been found to be incompatible with narrative engagement (e.g., Green \& Brock, 2000; McQueen, Krueter, Kalesan, \& Alcaraz, 2011; Slater, 2002), narrative persuasion theory is largely premised on the assumption that individuals who are engaged with stories cannot easily 
partake in other activities requiring cognitive effort (e.g., Green \& Brock, 2000). That is, peoples' ability to do other types of processing outside of their total preoccupation with a narrative is an ability they should not be able to have, according to theories of narrative persuasion. The results of this study, however, suggest that this is an oversimplification. Participants in this study were able to engage in greater levels of self-referencing while viewing without compromising their ability to become immersed in the story. The results presented here provide some insight into how self-referencing can co-exist with narrative engagement while a story is being consumed, revealing something of a contradiction in the previously established nature of engagement. It appears that processes selfreferencing can co-occur with engagement, even though it necessarily requires viewers to have some degree of self-awareness, and self-awareness is thought to be detrimental to the narrative engagement experience.

Second, the role that self-referencing plays in narrative persuasion was explored by examining differences in the degree of persuasive outcomes when people are instructed to engage with a narrative compared to when people are asked to self-reference during the same narrative. Notably, this study cannot offer any insight about whether one of these types of processing is more persuasive than the other because not only was narrative engagement not manipulated successfully, but there were no observed differences in persuasive outcomes between any of the experimental conditions as well. At best, one can conclude from these results that self-referencing does not detract from persuasion related outcomes.

Finally, the third goal of this project was to investigate whether what viewers do during viewing affects how much self-referencing occurs after the story. The findings 
show that regardless of the nature of the focusing task individuals were asked to perform while viewing the narrative, they engaged in the same amount of self-referencing when the story was finished. That is, according to the lack of differences in post-period selfreferencing found here, regardless of how people process stories in the moments they are exposed to them, this does not differentially impact their propensity to make personal connections back to the story afterwards.

In the remaining sections, implications for the current state of research on narrative persuasion and self-referencing are discussed in light of the findings of this study. In addition to discussing the primary findings of this research, a number of methodological considerations will be addressed as well, revealing both challenges and opportunities in the procedures for studying narrative persuasion processes. Practical and theoretical implications for health message designers and narrative persuasion researchers are presented throughout this discussion. Finally, a number of the study's limitations are detailed and paired with suggestions for future research.

\section{The Co-Occurrence of Narrative Processes}

One of the loftier goals of this study was to examine the theoretical argument that narrative engagement and self-referencing should not be able to happen simultaneously while viewing a narrative. The various models of narrative persuasion assert that a requirement of the experience of absorption or engagement is that individuals temporarily forget themselves and their surroundings so that they can be swept away into the world of the story (e.g., Busselle \& Bilandzic, 2009; Green \& Brock, 2000; Slater \& Rouner, 2002). Self-referencing on the other hand requires people to think about themselves in comparison to their environment (Burnkrant \& Unnava, 1995). Thus, self-referencing 
requires individuals to effectively step-outside of the story in order to consider the self while narrative engagement requires continued focus on the story itself. Therefore, it was reasoned that intense focus on one task should detract from viewers' ability to engage in the other. In order to test this argument, it was predicted that those asked to do one process should demonstrate less of an ability to do the other process.

Additionally, in the interest of gaining a better understanding about how selfreferencing and narrative engagement coexist, two comparison conditions were added to the study. The mixed directions condition served to show what happens when people are asked to do both processes, while the no directions condition was meant to reveal what happens naturally when people are not asked to do either process. If it were true that individuals who engage with the narrative cannot perform self-referencing and vice versa, then there should be an inverse relationship between these two variables. Specifically, those instructed to self-reference should report lower levels of narrative engagement, and those instructed to immerse in the narrative should have their ability to self-reference compromised. Because the narrative engagement manipulation was unsuccessful in this research, there was no way to compare the effects of narrative engagement on selfreferencing. In this study, the successful manipulation of self-referencing only permits inference into the unique role of self-referencing in the narrative persuasion process. However, increases in self-referencing had no bearing on the amount of narrative engagement viewers reported. These findings demonstrate that self-referencing does not compromise participants’ ability to engage with the narrative.

Finding that self-referencing can occur and not decrease narrative engagement highlights the fleeting nature of narrative engagement. The way that narrative 
engagement and transportation have been described in past research may give the impression that narrative engagement is an all-immersive, and continual process. For example, the experience has been described as "a convergent process, where all mental systems and capacities become focused on events occurring in the narrative” (Green \& Brock, 2000, p. 701), as “being primarily engaged in the storyline, rather than in one’s immediate environment” (Moyer-Gusé, 2008, p. 409), and a time when “people pay close attention to the details of the story and become engrossed or absorbed by it” (Tal-Or \& Cohen, 2010, p. 402). In other words, literature on narrative persuasion conceptualizes absorption into a narrative as a process by which a person has to shut down all other processes in order to completely focus on the story (Green \& Brock, 2000). Then, and only then, can people pay attention, create imagery, feel a sense of presence in the storyworld, comprehend the complexity of the narrative, and become emotionally involved with the plot and characters (e.g., Busselle \& Bilandzic, 2009; Green \& Brock, 2000). Prominent models of narrative persuasion continue to assert that a loss of self-awareness, a psychological distancing from reality, and a shifting of an individual’s center of experience from their world to the story-world are required for engagement to occur. In that way, engagement is defined by a period of no self-awareness where people completely lose touch with not only themselves, but also their environment, time and space, personal beliefs, and even real-world facts they know to be true. This led to the prediction that other processes-particularly one that depends on self-awareness - could not co-occur with narrative engagement.

However, although people may “lose themselves” during narrative engagement (Green, Chatham, \& Sestir, 2012, p. 37), this is likely not a sustained experience. That is, 
it is important to emphasize that engagement is likely not a constant state of mind that persists with consistent intensity from the start through the end of a narrative. Identification with characters has also been described as a "fleeting” experience (e.g., Cohen, 2001, p. 250; see also Wilson, 1993). Identification has been argued to be intermittent and momentary, meaning that people consuming narratives move in and out of shifting identities between themselves and the characters (Tal-Or \& Cohen, 2010). Although narrative engagement is conceptualized as a continuous process, the conceptual argument behind identification is that people move in and out of identity adoption, a necessary part of narrative engagement. Assuming that a similar experience occurs during narrative consumption, people should have the ability to think about themselves throughout the duration of a story if they break their engagement momentarily to contemplate the self before moving back into a state of engagement. This explains why viewers could self-reference without compromising their immersive experience in the narrative. Presumably, they could have alternated between a state of engagement and a state of self-referencing.

Of course, this study was never premised on the assumption that people could not switch back and forth between different types of narrative processing during viewing. It was, however, premised on the idea that engaging in more of one type of process during the story should lessen the extent that viewers can engage in other processes during the same time period. In other words, that the more people engaged in self-referencing during the narrative, the less time and effort they were expected to spend engaged with the narrative. The fact that this was not the case suggests that the nature of narrative engagement could be somewhat different than how it is often conceptualized. Perhaps 
self-referencing is a component of the narrative engagement experience. In their original statement of transportation into narrative worlds (narrative engagement), Green and Brock (2000) operationalized the process with a self-referencing component built in; their transportation scale includes self-referencing item (i.e., "the events in the narrative are relevant to my everyday life”). In fact, one reason that the transportation scale was not used in the current research is because of a concern that the scale would overlap with the self-referencing measure. In addition, Green and Brock found a moderate positive association between issue involvement and transportation, demonstrating that finding issues presented in a story as personally relevant can be positively related to how absorbed a person is in a story. Even in the current research, contrary to what was predicted, engagement and self-referencing during the narrative were positively correlated, suggesting that not only are they compatible processes, they are complimentary. Nonetheless, despite the fact that narrative engagement has traditionally been conceptualized as an experience removed from the self, the self-referencing item remains a part of the transportation scale. This contradiction has yet to be addressed, but the results suggest that the original operationalization of narrative engagement (i.e., the transportation scale), could reflect the true nature of narrative engagement. Perhaps the conceptualization of narrative engagement as a process devoid of self-processing is overly restrictive. Perhaps self-referencing is a part of the narrative engagement process. That is, self-referencing seems to be quite compatible with narrative engagement and so including it in measurements of transportation may not be so imprudent after all. However, it may be worth revisiting the narrow conceptualization of the narrative engagement experience and considering how people may be able to bring themselves and 
their experiences into the story world. In sum, engagement and self-referencing during a narrative do seem to be processes that can both happen over the course of exposure to a story.

\section{The Impact of Self-Referencing During a Narrative on Persuasion}

This study set out to examine how well self-referencing can encourage storyconsistent persuasive outcomes in comparison to engagement, as both have the potential to lead to persuasion. Engagement as a persuasive mechanism has been theorized to be effective for several reasons including a loss of access to real-world facts and beliefs reducing counterarguing (Green \& Brock, 2000), and perspective-taking of other individuals in the form of characters as well as emotional attachments to these characters (Cohen, 2001; Green \& Brock, 2000). Self-referencing is considered an effective persuasive mechanism because when messages seem personally relevant they are more easily able to be recalled (Kupier \& Rogers, 1979) and personally relevant messages have more persuasive potential (Krueter \& Wray, 2003). Unfortunately, because the narrative engagement manipulation failed, a comparison between the narrative engagement and self-referencing conditions and their influence on persuasion in the context of healthbased narratives cannot be made. However, given that self-referencing appears not to inhibit the narrative engagement processes, this comparison may be moot anyway. The results of this research strongly suggest that there is no need to choose between encouraging self-referencing or narrative engagement. Communication practitioners can encourage both processes with no detriment to either.

What can be said in light of the findings is that self-referencing did not increase persuasion. That is, in comparison to people who were self-referencing less, the people 
who were self-referencing more were no more persuaded by the story. This result was unexpected considering that past research has demonstrated that when people think about how information relates to themselves, it makes the information more personally relevant (Kupier \& Rogers, 1979) and ultimately potentially more persuasive (Krueter \& Wray, 2003). Likewise, even in the context of narratives, perceptions of similarity of characters (i.e., characters that are personally relevant) leads to persuasive outcomes when selfreferencing occurs in response to these perceptions (de Graaf, 2014). Based on these findings this study predicted that engaging in more self-referencing would be more persuasive than engaging in less self-referencing. However, this was not the case, and it is possible this was due to narrative engagement suppressing the effects of selfreferencing. In some past research (e.g., Burnkrant \& Unnava, 1995), increased selfreferencing only led to increased persuasion when participants were not elaborating on other parts of a message. Therefore, it is possible that participants in the current study were considering other parts of the narrative messages besides their relation to the self and as such, increased self-referencing was not more persuasive than less selfreferencing.

The findings in this study also suggest that it is possible for health communication message designers to encourage self-referencing in order to encourage audiences to relate their messages to themselves. That is, because the self-referencing manipulation was successful, one can conclude that people can be pushed towards relating to health messages in stories. This finding is encouraging because self-referencing can be promoted by providing people with simple instructions, and although self-referencing was not found to be persuasive in the current study, others have found it to be persuasive 
(e.g., Burnkrant \& Unnava, 1995; de Graaf, 2014). Just as in this study, message designers could create messages that instruct their target audience to keep their own experiences in mind as they continue to engage with the health narratives and their messages. An alternative method could be for campaign designers to ask their audience rhetorical questions after exposure their narratives. For example, they might ask the audience if there are any aspects of the story they just experienced that remind them of their own lives. Either way, instructing the public to self-reference in relation to these health messages could result in positive outcomes. For instance, self-referencing in this study was positively related to positive attitudes towards talking to partners about an STI diagnosis and intentions to talk to partners about STIs. Increased self-referencing in this study also did not increase counterarguing against persuasive messages made in the narrative about risky sexual behaviors and talking to partners about STIs.

Additionally, the supplemental analyses performed here suggest that narrative engagement may have an impact on some persuasive variables. Specifically, narrative engagement predicted positive attitudes towards talking about one's own STI status to both their past and current partners. Therefore, although engagement was not successfully manipulated in this study, the phenomenon of narrative engagement experienced during story exposure itself influences persuasive outcomes in some cases. In these analyses, self-referencing did not predict any persuasive outcomes, nor did the interaction between self-referencing and engagement suggesting that at least here, relating the story to the self does not differentially impact attitudes or intentions and it does not impact the effect engagement has on persuasion. 
In sum, although self-referencing did not affect any persuasive outcomes in this research, but there is no reason to think that this process cannot still have beneficial effects in response to other persuasive messages. Fortunately, the findings of this study also suggest that encouraging people to think about the self in relation to health threats while exposed to narratives is not only possible, but it can be done safely without increasing defensive processing, a finding that elaborated on further below. Additionally, narrative engagement has some persuasive benefit, which is in line with past research on narrative persuasion.

\section{The Relationship between Self-Referencing and Counterarguing}

It was previously proposed that if individuals’ cognitive capacities are taken up by the task of self-referencing during a story then they might not be able to counterargue against the persuasive messages, consistent with past research. For example, Green and Brock (2000) asked participants to evaluate the literacy level of a story for its difficulty and in doing so demonstrated that performing task during exposure lessens peoples’ absorption, which then increases their ability to argue. The other possibility proposed was that when people are prompted to think about risky health information such as STIs and how these risks may be relevant to themselves, they may begin to counterargue as a defensive strategy (e.g., Greenwald \& Leavitt, 1984; McQueen, Vernon, \& Swank, 2012). This study did not detect any differences in the amount of counterarguing that people who were asked to self-reference performed in comparison to those who did not. In other words, self-referencing more compared to self-referencing less did not differentially impact counterarguing against the messages in the story. 
Previous literature examining how people process risky health information has demonstrated that when they are engaged in or could begin to become engaged in risky behaviors, they move through stages of defensive strategies to avoid thinking about the information. People have been shown to move through the stages of attention avoidance, blunting, suppression, and counterarguing (McQueen, Vernon, \& Swank, 2012), meaning they avoid paying attention to risk information, avoid trying to comprehend it, deny the personal relevance of it, and possibly reject the message all together (i.e., counterarguing). In this study, self-referencing in response to a narrative about the consequences of risky sexual activity did not increase counterarguing, and the inverse relationship between counterarguing and self-referencing suggests that thinking about the self does not increase message resistance.

Although this defensive processing in response to risk information has been found in some studies, perceiving personal risk is also said to be a necessary prerequisite for changing health behaviors (de Wit, Das, \& Vet, 2008) meaning that some attention to personal risk messages must occur before the messages can have persuasive influence (at least in the form of behavior change). Because defensive processing has been shown to decrease while people are viewing narratives in the past, narratives might be a context where perceiving risk through self-referencing does not activate or increase defensive processing. Narratives have also been found to be a superior method of communicating personal risk to people in comparison to statistical evidence due to their effect of reducing counterarguing (de Wit, Das, \& Vet, 2008). If such is the case, self-referencing may not have increased counterarguing against points made in the narrative here because narratives are a context in which people argue against persuasion less. 
All in all, showing that individuals who personally relate to health narratives are not more likely to counterargue against the persuasive messages suggest that selfreferencing can be a useful tool for persuasion, without much risk of backfiring in greater persuasive resistance. Viewers in the current study who were instructed to self-reference related the story back to themselves, but they did not appear to be doing so in a defensive way that would increase resistance to the message. This possibility could be confirmed by examining the content of the self-referencing viewers generated during viewing and determining if it was more consistent or inconsistent with the persuasive messages in the episode. This is a fruitful area for future research.

\section{Self-Referencing After a Narrative}

How people process narrative messages after they are over is as important to understand as how people process the messages during the narrative as this after period may impact persuasive outcomes. For instance, it was argued based on work by Slater and Rouner (2002) that the post-exposure period gives people the chance to think more deeply about the messages because they are finished with being engaged. That is, this post-period may be a time where reflection on the message occurs if that reflection was unable to take place during exposure. Relatedly, if people are highly absorbed into a narrative they should not be able to think about how their own lives relate to the message during that absorption. Therefore, it was suggested that self-referencing during a narrative may be a suppressed ability if a person is narratively engaged, but that that suppression should cease once the story has concluded and people should once again be free to think about themselves. Therefore, individuals in the current study were given the opportunity to have a post-viewing reflection period where they could contemplate 
anything they wanted in relation to the story, and their self-referencing thoughts were counted to examine potential differences in post-thoughts based on during-narrative processing.

Unfortunately, because the narrative engagement manipulation was ineffective, it was not possible to observe the effects of narrative engagement on post-viewing selfreferencing. What the findings of this research do show, however, is that those who instructed to self-reference during narrative exposure did not engage in any more or less self-referencing after the story compared to those who were not instructed to selfreference during exposure. At the very least it can be concluded that self-referencing did not beget more self-referencing. If there are any persuasive advantages of self-referencing during story consumption, it seems reasonable to conclude that additional selfreferencing in the post-exposure period is not one of them. Viewers are just as likely to generate self-referenced thoughts after-exposure, regardless of whether they were doing it during exposure. If self-referencing after the story is considered to be a beneficial process, this is encouraging news: One need not work to encourage greater selfreferencing during a narrative as it has no bearing on how much self-referencing occurs after the narrative.

Recall that one of the original arguments in this study was that because people who are narratively engaged with a story should not be able to self-reference during story exposure, they may still engage in self-referencing, but they may do so after the story, post-narrative engagement. However, as previously discussed, because those who were performing more self-referencing during exposure did not report less narrative engagement than others, it stands to reason that self-referencing can occur during 
narrative engagement. Hence, it stands to reason that the post-exposure period may not actually be necessary for relating messages back to the self in the context of narratives because people are able to self-reference during the narrative (i.e., they do not need the extra post-exposure period). Past empirical work on media with narratives such as television shows and video games that have examined the post-exposure period demonstrates the persuasive process is still at work once a story concludes. For example, this post-period is a time when people elaborate on narrative messages and report more favorable attitudes consistent with stories when they identify with characters (Igartua \& Casanova, 2016). As another example, people who are absorbed in persuasive games have been shown to use the time between gameplay to reflect on their experiences, which influences persuasion (Klimmt, 2009). Similarly, this study did find that when participants were given the opportunity to share thoughts about the episode, many of those thoughts were categorized as the type of self-referencing that can facilitate persuasion. This is further evidence that the persuasive process extends beyond viewing. However, the findings from this study indicate that the amount of post-exposure selfreferencing is unlikely to be affected by the extent that people are asked to self-reference during viewing.

It is important to note that no persuasion-related measures were taken after this post-exposure thinking period occurred and so the effect that self-referencing after a story has on story-related persuasion remains unknown. A test of the persuasive influence of post-exposure self-referencing was beyond the scope of this research, and thus it is unclear how the thoughts that were generated in the post-exposure period impact message reception and affect healthy attitudes, behavioral intentions, and so on. In order to gain a 
better understanding of the role post-exposure self-referencing thoughts have on persuasion, story-consistent persuasive outcome measures would need to be taken sometime after the thought-listing period, either immediately or in a follow-up study (i.e., if considering effects on persuasion persistence). Although self-referencing is assumed to be beneficial in that it can help with recalling messages and increasing personal relevance, how self-thoughts that occur after the narrative impact persuasion variables is still an open question.

\section{Limitations and Future Directions}

As with all research, this study had several limitations but also sheds light on opportunities to improve future narrative persuasion research. First, the manipulation for narrative engagement used in this study was problematic. Asking individuals to engage with the narrative did not lead to more engagement, meaning that engagement was not manipulated successfully in this study. It did not matter if people were asked to engage or not; they engaged with the narrative almost equally across all four conditions. This failure to introduce variability in peoples' narrative engagement compared to what occurs naturally is in line with past research and as such, is not the first time this failure has occurred. For example, Green (2004) gave written instructions to participants, but it did not change their degree of transportation. As per Green's recommendations, the current study provided written instructions with much more detail on what participants should be focused on and was designed to invoke responses in people that mimic the various components of narrative engagement. Again, however, this attempt was also unsuccessful. 
It is possible that this failure occurred because the degree of narrative engagement people experience may not be able to be increased. Past studies have successfully decreased engagement by giving people a distracting task (Green \& Brock, 2000), but thus far, no one has been able to increase engagement beyond the engagement that occurs naturally. Of note, an examination of the means of reported narrative engagement across the four conditions shows that regardless of condition, narrative engagement remained relatively high (see Table 3). That is, the reported means across all conditions were a full point or more above the midpoint of the scale. This is notably higher than viewers' reported self-referencing, which sat below or closer to the midpoint than reported narrative engagement. This lends some support the argument that people are naturally inclined to become narratively engaged with stories. This may be one reason that narrative engagement is so challenging to manipulate. There may be a built in ceiling effect. Narrative engagement comes easy, regardless of whether viewers are instructed to do so or not. On the other hand, even though self-referencing was manipulated successfully in this research, being told to relate oneself to the story only resulted in relatively weak amounts of self-referencing. Self-referencing appears to require a more concerted effort on the part of audiences.

Another possibility is that the conceptualization of engagement may be flawed, leading to an inability to increase engagement. As previously discussed, engagement has been conceptualized as a process where processes outside of engagement (i.e., any process that is outside of the story such as self-referencing) cannot occur, but evidence would suggest differently. In this study, for example, self-referencing was able to occur over the duration of exposure, and those that were self-referencing more did not show 
any negative impact on their degree of story-consistent persuasion outcomes. Therefore, it may be prudent for researchers to first consider that engagement is a time period where other processes can co-occur along with that engagement before attempting to manipulate it in future studies.

To date, the manipulation of narrative engagement persists as an elusive goal for researchers presenting problems for research of narrative persuasion. One main goal of narrative research is to make sense of narrative processes and how they affect persuasion, and countless studies have shown a relationship between narrative engagement (and related concepts) and persuasion. However, to my knowledge, no empirical study has been able to demonstrate a causal relationship between narrative engagement and persuasive outcomes because of the inability to successfully affect the extent to which people engage with stories. Thus, there remains no way of isolating narrative engagement effects, and determining, definitively, that variation in narrative engagement (as opposed to other narrative experiences) is what causes differences in persuasion-related outcomes. Therefore, before researchers can make the causal claim that narrative engagement positively impacts persuasion, a conceptualization that more closely represents the true nature of engagement must be put forth and a successful manipulation of the construct must be performed.

The self-referencing manipulation used in this study, on the other hand, was successful. Importantly, although the manipulation appeared to work, when asked to describe how some of their thoughts were self-referencing thoughts in the post-exposure period, there were many times (i.e., 151 times; $28.1 \%$ of the time) participants did so incorrectly. In other words, although the manipulation itself did what it was intended to 
do (i.e., it increased self-referencing during story consumption), there were aspects about the survey instructions about self-referencing that were unclear to participants for the post-exposure part of the experiment. This study greatly depended on participants' ability to comprehend and follow specific directions, and it seems from some of the results that many participants in this sample were not able to do so when instructed to code their own thoughts for self-referencing. In future work that uses self-referencing thought-listing techniques, it may be wise to provide participants with a list of examples of what does and does not constitute self-referencing. Observation of the thoughts that participants incorrectly identified suggests that many participants (i.e., 66) misunderstood what selfreferencing is despite efforts to clarify this in the instructions. Providing examples may make the conceptualization of self-referencing more clear to participants. For instance, it can be explained to them that self-referencing thoughts have occurred if they talk about a time an event happened to them (e.g., "I have been diagnosed with HPV”), discuss how a decision made in the story is similar to one they have made (e.g., "I had to talk to my partner about STI testing”), or if they explain how they previously knew information presented in the story (e.g., "I already knew men could not be tested for HPV”). This suggestion could also be used when trying to manipulate engagement as well in that a list of what engagement is and is not could be helpful for participants in future studies.

Another limitation of this study is that the self-referencing data collected during the post-viewing period were only analyzed quantitatively, not permitting any investigation into the nuances of the types of self-referencing that viewers engaged in. A qualitative analysis would permit a look at the various types of thoughts people may be having about their relationship to the story. For example, were respondents considering 
personal experiences that resembled what they saw in the narrative, or were they considering how they have never talked to their partner about STI testing? In the first case, the person would be expressing similarity between the storyline and their own life, but in the second case, they would be explaining how the story made them realize something about their past and future behaviors and would be more in-line with storyconsistent persuasion. The takeaway is that without some qualitative analysis of the content of these thoughts, it is unclear what types of thoughts participants were having and it is also unclear if these thought types varied based on the processing instructions they received. Although such an analysis was outside of the scope of this study, future empirical work in this area could approach the data in a more qualitative manner in order to get a more rich understanding of how processing narratives differently may differentially impact self-referencing thoughts.

As previously discussed, this research did not detect any differences in how the different narrative processing strategies affected viewers' adoption of story-consistent attitudes and behavioral intentions. Although this could be because processes like selfreferencing played no role in the persuasive process, alternatively, this could be because the stimulus episode used in this project did not persuade participants at all. Because this study did not include a control stimulus it is not possible to determine whether the Girls episode used in this research changed participants' thoughts and feelings related to STIs. Comparing the responses of those exposed to the episode to the responses of those exposed to an unrelated episode would have made it possible to determine whether the episode resulted in any persuasive outcomes. Future research on narrative persuasion 
processes should be mindful to ensure that the any stories employed for study are effectively influential.

Additionally, the episode used in this particular research had a mix of messages with more than one persuasive direction. That is, the episode presented contrary messages and impressions about HPV at times. For example, some messages seemed to be more prevention-based (e.g., get tested for STIs) while others seemed to be downplaying the severity of HPV (e.g., it is socially normative and acceptable to have HPV). The nature of the stimulus may have contributed to low scale reliabilities for counterarguing and attitudes towards talking to partners about an STI diagnosis, and may also explain the lack of persuasion demonstrated. For instance, if some viewers took away positive impressions of disclosing their STI status to their partner but others took away negative impressions, this could have dampened the overall persuasive impact of the episode. Future research using episodes that contain mixed health messages might ask their participants to describe the take-away messages they received from the stimulus in order to examine if participants are leaving with impressions that are contrary to the overall intended persuasive direction of the story.

An additional limitation of this study was that the design of the experimental manipulations, which gave participants detailed instructions on how they should conduct themselves during the experiment, could have introduced demand characteristics. Participants in both the self-referencing condition and the mixed instructions condition reported engaging in more self-referencing during viewing. But there is no definitive way to determine whether participants who reported engaging in self-referencing were actually self-referencing or instead, reporting that they had been self-referencing because 
they knew that was their assignment. Nonetheless, it seems unlikely that participants in these conditions were fabricating or even exaggerating the extent that they actually engaged in self-referencing. If a demand characteristic was responsible for these differences between conditions, one would expect it to manifest in the narrative engagement condition as well. That is, participants in the engagement condition should be equally as motivated to overestimate the extent that they were engaged. However, this was not the case. Therefore, it appears that those in the self-referencing condition were actually involved in that activity and not just reporting that they were due to knowing what the experimenter was looking for. Demand characteristics are an issue with many experimental designs such as the one used here. Instructing participants on what to do may always have at least some influence on what they self-report doing during the study, which should be a consideration in future research designs.

Finally, as with many studies, the sample used here was a convenience sample of undergraduate college students and as such, the results of the study should be generalized to other populations with caution. However, for the particular narrative used in this study, a college sample may have actually been the best choice of a sample because the target demographic of the show used (i.e., Girls) as the stimulus is young adults. Additionally, college students have been found to have a perception of vulnerability to STIs that is unrealistically low, meaning they report low susceptibility to contracting STIs (Scholly, Katz, Cole, \& Heck, 2010). This makes them a challenging demographic to target when trying to change sexual health behaviors, but using a show that appeals to young viewers may be an effective way to transmit persuasive messages to them about their sexual health. Because the narrative used in this study followed several young adults as they 
navigated discussions with each other over STIs, a health topic that is salient to college students, the sample was nonetheless a fitting match for the stimulus.

\section{Conclusion}

This study looked at engagement and self-referencing in the context of narratives to explore their impact on persuasion using a health-related storyline as well as examined how they co-occur over the duration of the total narrative experience. An experiment was conducted in order to address the three main goals laid out in the study. It was found that self-referencing in relation to a story does not detract from a person's ability to engage with a story, nor from how consistent their beliefs, intentions, and other persuasionrelated outcomes are with the storyline’s. It was also found that differences in approaches to processing a narrative has no bearing on how much people relate the story to themselves after reflecting on the story. Overall, this study contributes to the narrative persuasion literature in that it sheds light on how different mechanisms that can lead to persuasion through stories function together and separately. The results of the study also brought to light some methodological challenges associated with narrative persuasion research and provide suggestions for future empirical work in this area. In summary, the way that narrative researchers conceptualize narrative engagement as a mechanism for persuasion needs to be revisited before research attempting to manipulate this process continues. Self-referencing and its relationship to narratives should also continue to be explored as it seems to be a promising route to producing narrative persuasion when working in tandem with engagement. 


\section{References}

Abelson, R.P. (1987). Artificial intelligence and literary appreciation: How big is the gap? In L. Halsaz (Ed.), Literary discourse (pp. 38-48). Amsterdam: de Gruyter.

Appel, M., \& Richter, T. (2010). Transportation and need for affect in narrative persuasion: A mediated moderation model. Media Psychology, 13, 101-135. doi:10.1080/15213261003799847

Berger, J., \& Milkman, K. L. (2012). What makes online content viral? Journal of Marketing Research, 49, 192-205. doi:10.1509/jmr.10.0353

Bizer, G. Y., \& Krosnick, J. A. (2001). Exploring the structure of strength-related attitude features: The relation between attitude importance and attitude accessibility. Journal of Personality and Social Psychology, 81, 566-586. doi:10.1037/0022-3514.81.4.566

Black, J.B. and Seifert, C.M. (1985). The psychological study of story understanding. In C. R. Cooper (Ed.), Researching response to literature and the teaching of literature, (pp. 190-211). Norwood, NJ: Ablex.

Bruner, J.S. (1986). Actual minds. Possible worlds. Cambridge: Harvard University Press.

Burnkrant, R. E., \& Unnava, H. R. (1989). Self-referencing: A strategy for increasing processing of message content. Personality and Social Psychology Bulletin, 15, 628-638. doi:10.1177/0146167289154015

Burnkrant, R. E., \& Unnava, H. R. (1995). Effects of self-referencing on persuasion. Journal of Consumer Research, 22, 17-26. doi:10.1086/209432 
Busselle, R., \& Bilandzic, H. (2008). Fictionality and perceived realism in experiencing stories: A model of narrative comprehension and engagement. Communication Theory, 18, 255-280. doi:10.1111/j.1468-2885.2008.00322.x

Busselle, R., \& Bilandzic, H. (2009). Measuring narrative engagement. Media Psychology, 12, 321-347. doi:10.1080/15213260903287259

Center for Disease Control [CDC] (2017a). Genital HPV infection - Fact sheet. Retrieved from https://www.cdc.gov/std/hpv/stdfact-hpv.htm Center for Disease Control [CDC] (2017b). HPV and men - Fact sheet. Retrieved from https://www.cdc.gov/std/hpv/stdfact-hpv-and-men.htm

Chen, M., Bell, R. A., \& Taylor, L. D. (2016). Narrator point of view and persuasion in health narratives: The role of protagonist-reader similarity, identification, and selfreferencing. Journal of Health Communication, 21, 908-918.

doi:10.1080/10810730.2016.1177147

Chen, M., Bell, R. A., \& Taylor, L. D. (2017). Persuasive effects of point of view, protagonist competence, and similarity in a health narrative about type 2 diabetes. Journal of Health Communication, 22, 702-712. doi:10.1080/10810730.2017.1341568

Cohen, E. L. (2016). Exploring subtext processing in narrative persuasion: The role of eudaimonic entertainment-use motivation and a supplemental conclusion scene. Communication Quarterly, 64, 273-297. doi:10.1080/01463373.2015.1103287 
Cohen, J. (2001). Defining identification: A theoretical look at the identification of audiences with media characters. Mass Communication \& Society, 4, 245-264. doi:10.1207/S15327825MCS0403_01

Cohen, E. L., Alward, D., Zajicek, D., Edwards, S., \& Hutson, R. (2017). Ending as intended: The educational effects of an epilogue to a TV show episode about bipolar disorder. Health Communication. Advanced online publication. doi:10.1080/10410236.2017.1331308

Csikszentmihalyi, M. (1990). Flow: The psychology of optimal performance. New York, NY: HarperCollins.

Dal Cin, S., Zanna, M. P., \& Fong, G. T. (2004). Narrative persuasion and overcoming resistance. In E. S. Knowles \& J. A. Linn (Eds.), Resistance and persuasion (pp. 175-191). Mahwah, NJ: Erlbaum.

de Graaf, A. (2014). The effectiveness of adaptation of the protagonist in narrative impact: Similarity influences health beliefs through self-referencing. Human Communication Research, 40, 73-90. doi:10.1111/hcre.12015

de Wit, J. B., Das, E., \& Vet, R. (2008). What works best: Objective statistics or a personal testimonial? An assessment of the persuasive effects of different types of message evidence on risk perception. Health Psychology, 27, 110-115. doi:10.1037/0278-6133.27.1.110

Duchan, J. F., Bruder, G. A., \& Hewitt, L. E. (1995). Deixis in narrative: A cognitive science perspective. Hillsdale, NJ: Erlbaum.

Dunlop, S. M., Wakefield, M., \& Kashima, Y. (2010). Pathways to persuasion: Cognitive and experiential responses to health-promoting mass media 
messages. Communication Research, 37, 133-164.

doi:10.1177/0093650209351912

Escalas, J. E. (2006). Self-referencing and persuasion: Narrative transportation versus analytical elaboration. Journal of Consumer Research, 33, 421-429. doi:10.1086/510216

Fortenberry, J. D., McFarlane, M., Bleakley, A., Bull, S., Fishbein, M., Grimley, D. M., ... \& Stoner, B. P. (2002). Relationships of stigma and shame to gonorrhea and HIV screening. American Journal of Public Health, 92, 378-381. doi:10.2105/AJPH.92.3.378

Frank, L. B., Murphy, S. T., Chatterjee, J. S., Moran, M. B., \& Baezconde-Garbanati, L. (2015). Telling stories, saving lives: Creating narrative health messages. Health Communication, 30, 154-163. doi:10.1080/10410236.2014.974126

Gerrig, R. J. (1993). Experiencing narrative worlds: On the psychological activities of reading. New Haven, CT: Yale University Press.

Green, M. C. (2004). Transportation into narrative worlds: The role of prior knowledge and perceived realism. Discourse Processes, 38, 247-266. doi:10.1207/s15326950dp3802_5

Green, M. C., \& Brock, T. C. (2000). The role of transportation in the persuasiveness of public narratives. Journal of Personality and Social Psychology, 79, 701-721. doi:10.1037/0022-3514.79.5.701

Green, M. C., \& Brock, T. C. (2002). In the mind's eye: Transportation-imagery model of narrative persuasion. In M. C. Green, J. J. Strange, \& T. C. Brock 
(Eds.), Narrative impact: Social and cognitive foundations (pp. 315-341). Mahwah, NJ: Erlbaum.

Green, M. C., Brock, T. C., \& Kaufman, G. F. (2004). Understanding media enjoyment: The role of transportation into narrative worlds. Communication Theory, 14, 311327. doi:10.1111/j.1468-2885.2004.tb00317.x

Green, M. C., Chatham, C., \& Sestir, M. A. (2012). Emotion and transportation into fact and fiction. Scientific Study of Literature, 2, 37-59. doi:10.1075/ssol.2.1.03gre

Greenwald, A. G., \& Leavitt, C. (1984). Audience involvement in advertising: Four levels. Journal of Consumer Research, 11, 581-592. doi:10.1086/208994

Hayes, A. F. (2018). Introduction to mediation, moderation, and conditional process analysis: A regression-based approach ( $2^{\text {nd }}$ ed.). New York, NY: Guilford Publications.

Hinyard, L. J., \& Kreuter, M. W. (2007). Using narrative communication as a tool for health behavior change: A conceptual, theoretical, and empirical overview. Health Education \& Behavior, 34, 777-792. doi:10.1177/1090198106291963

Hoffner, C. (1996). Children's wishful identification and parasocial interaction with favorite television characters. Journal of Broadcasting \& Electronic Media, 40, 389-402. doi:10.1080/08838159609364360

Ibrahim, A., Ye, J., \& Hoffner, C. (2008). Diffusion of news of the shuttle Columbia disaster: The role of emotional responses and motives for interpersonal communication. Communication Research Reports, 25, 91-101. doi:10.1080/08824090802021970 
Igartua, J. J., \& Casanova, J. V. (2016). Identification with characters, elaboration, and counterarguing in entertainment-education interventions through audiovisual fiction. Journal of Health Communication, 21, 293-300. doi:10.1080/10810730.2015.1064494

Klimmt, C. (2009). Serious games and social change: Why they (should) work. In P. Vorderer, U. Ritterfeld, \& M. J. Cody (Eds.), Serious games: Mechanisms and effects (pp. 248-270). New York, NY: Routledge.

Kreuter, M. W., Bull, F. C., Clark, E. M., \& Oswald, D. L. (1999). Understanding how people process health information: A comparison of tailored and nontailored weight-loss materials. Health Psychology, 18, 487-494. doi:10.1037/02786133.18.5.487

Kreuter, M. W., Holmes, K., Alcaraz, K., Kalesan, B., Rath, S., Richert, M., ... \& Clark, E. M. (2010). Comparing narrative and informational videos to increase mammography in low-income African American women. Patient Education and Counseling, 81, S6-S14. doi:10.1016/j.pec.2010.09.008

Kreuter, M. W., \& Wray, R. J. (2003). Tailored and targeted health communication: Strategies for enhancing information relevance. American Journal of Health Behavior, 27, S227-S232.

Kuiper, N. A., \& Rogers, T. B. (1979). Encoding of personal information: Self-other differences. Journal of Personality and Social Psychology, 37, 499-514. doi:10.1037/0022-3514.37.4.499 
Larsen, S. F., \& Seilman, U. (1988). Personal remindings while reading literature. Textinterdisciplinary Journal for the Study of Discourse, 8, 411-430. doi:10.1515/text.1.1988.8.4.411

McQueen, A., Kreuter, M. W., Kalesan, B., \& Alcaraz, K. I. (2011). Understanding narrative effects: The impact of breast cancer survivor stories on message processing, attitudes, and beliefs among African American women. Health Psychology, 30, 674-682. doi:10.1037/a0025395

McQueen, A., Vernon, S. W., \& Swank, P. R. (2013). Construct definition and scale development for defensive information processing: An application to colorectal cancer screening. Health Psychology, 32, 190-202. doi:10.1037/a0027311

Moyer-Gusé, E. (2008). Toward a theory of entertainment persuasion: Explaining the persuasive effects of entertainment-education messages. Communication Theory, 18, 407-425. doi:10.1111/j.1468-2885.2008.00328.x

Moyer-Gusé, E., Jain, P., \& Chung, A. H. (2012). Reinforcement or reactance? Examining the effect of an explicit persuasive appeal following an entertainmenteducation narrative. Journal of Communication, 62, 1010-1027. doi:10.1111/j.1460-2466.2012.01680.x

Moyer-Gusé, E., \& Nabi, R. L. (2010). Explaining the effects of narrative in an entertainment television program: Overcoming resistance to persuasion. Human Communication Research, 36, 26-52. doi:10.1111/j.1468-2958.2009.01367.x

Nabi, R. L. (2015). Emotional flow in persuasive health messages. Health Communication, 30, 114-124. doi:10.1080/10410236.2014.974129 
Nabi, R. L., \& Green, M. C. (2015). The role of a narrative's emotional flow in promoting persuasive outcomes. Media Psychology, 18, 137-162. doi:10.1080/15213269.2014.912585

Nabi, R. L., \& Krcmar, M. (2004). Conceptualizing media enjoyment as attitude: Implications for mass media effects research. Communication Theory, 14, 288310. doi:10.1111/j.1468-2885.2004.tb00316.x

Nabi, R. L., Moyer-Gusé, E., \& Byrne, S. (2007). All joking aside: A serious investigation into the persuasive effect of funny social issue messages. Communication Monographs, 74, 29-54. doi:10.1080/03637750701196896

Oliver, M. B., \& Bartsch, A. (2010). Appreciation as audience response: Exploring entertainment gratifications beyond hedonism. Human Communication Research, 36, 53-81. doi:10.1111/j.1468-2958.2009.01368.x

Petty, R. E., \& Cacioppo, J. T. (1986). The elaboration likelihood model of persuasion. Advances in Experimental Social Psychology, 19, 123-205. doi:10.1016/S0065-2601(08)60214-2

Petty, R. E., Cacioppo, J. T., Haugtvedt, C. P., \& Heesacker, M. (1986). Consequences of the route to persuasion: Persistence and resistance of attitude changes. Unpublished manuscript, University of Missouri, Columbia, MO.

Quintero Johnson, J. M., \& Sangalang, A. (2017). Testing the explanatory power of two measures of narrative involvement: An investigation of the influence of transportation and narrative engagement on the process of narrative 
persuasion. Media Psychology, 20, 144-173.

doi:10.1080/15213269.2016.1160788

Rimé, B. (1995). The social sharing of emotion as a source for the social knowledge of emotion. In J. A. Russel, J. M. Fernández-Dols, A. S. R., Manstead, \& J. C. Wellenkamp (Eds.), Everyday conceptions of emotion: An introduction to the psychology, anthropology, and linguistics of emotion (pp. 475-489). Norwell, MA: Kluwer Academic Publishers.

Rogers, T. B., Kuiper, N. A., \& Kirker, W. S. (1977). Self-reference and the encoding of personal information. Journal of Personality and Social Psychology, 35, 677-688. doi: 0.1037/0022-3514.35.9.677

Schank, R. C., \& Abelson, R. P. (1995). Knowledge and memory: The real story. In R. S. Wyer, Jr. (Ed.), Advances in social cognition (Vol. 8). Hillsdale, NJ: Erlbaum.

Scholly, K., Katz, A. R., Cole, D., \& Heck, R. H. (2010). Factors associated with adverse sexual outcomes among college students. American Journal of Health Studies, 25, 176-185.

Slater, M. D. (2002). Entertainment education and the persuasive impact of narratives. In M. C. Green, J. J. Strange, \& T. C. Brock (Eds.), Narrative impact: Social and cognitive foundations (pp. 157-181). Mahwah, NJ: Erlbaum.

Slater, M. D., \& Rouner, D. (2002). Entertainment—education and elaboration likelihood: Understanding the processing of narrative persuasion. Communication Theory, 12, 173-191. doi:10.1111/j.1468-2885.2002.tb00265.x 
Strange, J. J., \& Leung, C. C. (1999). How anecdotal accounts in news and in fiction can influence judgments of a social problem’s urgency, causes, and cures. Personality and Social Psychology Bulletin, 25, 436-449. doi:10.1177/0146167299025004004

Tal-Or, N., \& Cohen, J. (2010). Understanding audience involvement: Conceptualizing and manipulating identification and transportation. Poetics, 38, 402-418. doi:10.1016/j.poetic.2010.05.004

Wilson, T. (1993). Watching television: Hermeneutics, reception, and popular culture. Cambridge, England: Polity.

Witte, K. (1994). Fear control and danger control: A test of the extended parallel process model (EPPM). Communications Monographs, 61, 113-134.

doi:10.1080/03637759409376328 
Appendix A

Consent Information Form

\title{
Only Minimal Risk \\ Consent Information and HIPAA Form
}

\author{
Principal Investigator $\quad$ Elizabeth L. Cohen, Ph.D. \\ Department \\ Communication Studies \\ Protocol Number \\ 1802969633 \\ Study Title \\ Reactions to a Popular TV Show \\ Co-Investigator(s) \\ Julia K. Weiss, Ph.D. Candidate
}

\section{Contact Persons}

Elizabeth L. Cohen

If you have any questions, concerns, or complaints about this research, you can contact the principal investigator Dr. Elizabeth Cohen directly. She can be reached at (304) 2933905 or at

Elizabeth.Cohen@mail.wvu.edu. For information regarding your rights as a research subject, to discuss problems, concerns, or suggestions related to the research, to obtain information or offer input about the research, contact the Office of Research Integrity \& Compliance at (304) 293-7073. WVU IRB approval is on file.

\section{Introduction}

This research study is being conducted by Julia K. Weiss, a Ph.D. Candidate in the Department of Communication Studies at West Virginia University as part of her doctoral dissertation research. The study is supervised by Elizabeth L. Cohen, an Assistant Professor in the Department of Communication Studies. You have been asked to participate in this research study, which has been explained to you by Ms. Weiss. This project is not funded by any outside organization.

\section{Purpose(s) of the Study}

The purpose of this research study is to better understand how people focus on television shows about sexual health and how they feel about these programs.

\section{Description of Procedures}

In this single research study session, you will be asked to do two things: (1) watch an episode of a popular television show (rated TV-MA for Mature Audiences) for 20 minutes, and (2) complete a survey about your experiences with the television episode and your thoughts, which should take you approximately 25 minutes. You will arrive at the lab during your scheduled time slot and be given detailed instructions on what to do 
and how to fill out the survey. This research session is not expected to take more than 60 minutes.

\section{Discomforts}

The television episode that you will watch contains some sensitive material regarding a diagnosis of a sexually transmitted infection (STI). You will also be asked to respond to questions about your personal experience with STIs. The episode (rated TV-MA for Mature Audiences) or the questions may cause some people to feel uncomfortable. If you become uncomfortable or upset at any time, or if you simply no longer wish to continue your participation after you start for any reason, you may stop participating without penalty. In the event that you do experience extreme discomfort, you are invited to contact one of the following counseling services: a) the WVU Carruth Center at (304) 293-4431, b) Morgantown Counseling at (304) 290-7210, or c) APO Counseling at (304) 284-8438.

\section{Alternatives}

You do not have to participate in this research study.

\section{Benefits}

You will not receive any direct benefit from this research study.

\section{Financial Considerations}

There are no special fees for participating in this research study.

If you are enrolled in a Communication Studies course, you may be eligible to receive research credit (extra course credit) for participation in this research study. To find out if you are eligible, please contact your Instructor and/or your course syllabus. Your course syllabus should also include details regarding how many research credits you may be eligible for (as well as how many research opportunities you can attempt for that class). Students not wishing to volunteer for this research study are able to receive research credit by completing an alternative assignment. For students in eligible classes, your instructor will provide more information on the alternative assignment.

\section{Confidentiality}

Your participation and any information that is obtained as a result of your participation in this research will be kept as confidential as legally possible. The data collected from this research study will be kept on password-protected and firewall-protected computers accessible only by the researchers. We will keep the data you provide indefinitely, and we may use it in other studies. Your research records and test results, just like hospital records, may be subpoenaed by court order or may be inspected by federal regulatory 
authorities without your additional consent. Otherwise, only authorized researchers will have access to your responses.

\section{HIPAA}

We know that information about you and your health is private. We are dedicated to protecting the privacy of that information. Because of this promise, we must get your written authorization (permission) before we may use or disclose your protected health information or share it with others for research purposes. You can decide to sign or not to sign this authorization section. However, if you choose not to sign this authorization, you will not be able to take part in the research study. Whatever choice you make about this research study will not have an effect on your access to medical care.

\section{The Following Information Will Be Used}

Information about you that is collected during the study such as: self-reports of testing for sexually transmitted infections (STIs), whether you or anyone you know has been affected by STIs, and demographic data.

\section{The Information is Being Disclosed for the Following Reasons}

Publication of study results (without identifying you).

\section{You May Cancel this Authorization at Any Time by Writing to the Principal Investigator}

Elizabeth L. Cohen can be reached at (304) 293-3905 or at

Elizabeth.Cohen@mail.wvu.edu.

If you cancel this authorization, any information that was collected already for this study cannot be withdrawn. Once information is disclosed, according to this authorization, the recipient may redisclose it and then the information may no longer be protected by federal regulations.

This authorization will expire at the end of the study unless you cancel it before that time.

\section{Voluntary Participation}

Participation in this research study is voluntary. You are free to withdraw your consent to participate in this research study at any time. You do not have to answer any questions that you do not feel comfortable answering. At any point, you may skip over questions or stop responding and leave the research study. Refusal to participate or withdrawal will not affect your class standing or grades and will involve no penalty to you. In the event that new information becomes available that may affect your willingness to participate in this research study, this information will be given to you so that you can make an informed decision about whether or not to continue your participation. You have been given the opportunity to ask questions about the research, and you have received answers concerning areas you did not understand. 
Upon signing this form, you will receive a copy

I willingly consent to participate in this research.

\section{Signatures}

Signature of Subject

Printed Name

Date

Time

The participant has had the opportunity to have questions addressed. The participant willingly agrees to be in the study.

Signature of Investigator or Co-Investigator

Printed Name

Date Time 
Appendix B

\section{Recruitment Advertisement}

You are invited to participate in a research study about how people watch television shows. If you participate, you will be asked to:

1. Watch an episode of a popular television show in our research lab

2. Complete a survey with questions about your impressions of the episode, and questions about yourself related to the events depicted in the episode

Some of the questions that you will be asked concern personal or sensitive information. This could make you uncomfortable. But you can skip any questions or stop participating at any time. This research is completely voluntary!

This study will take place in the Communication Studies Research Lab in Armstrong Hall, on the WVU Campus. This study will take between 45 minutes and 1 hour of time, depending on how quickly you complete the survey.

You must be 18 years of age to participate in this research.

Eligible students may earn research credit (extra credit) for participation in this research study. To find out if you are eligible, please contact your instructor and/or your course syllabus. After completing the research, you will be given a receipt as evidence of your participation.

This study is being administered by Ms. Julia K. Weiss (jkweiss@mix.wvu.edu) under the supervision of Dr. Elizabeth Cohen (elizabeth.cohen@mail.wvu.edu), in the Department of Communication Studies. Dr. Cohen is the principal investigator for this research. Both Dr. Cohen and Ms. Weiss can be reached by telephone at (304) 293-3905, or in person in 108 Armstrong Hall on the WVU campus (P.O. Box 6293, Morgantown, WV, 26506).

Approval of this study is on file with the West Virginia University Institutional Review Board at (protocol \#1802969633).

We sincerely appreciate your help!

To participate in the study, you must make an appointment though our scheduling website, SONA. If you don't already have an account, you can quickly set one up before you make your appointment.

Please use the link to SONA below to make your appointment! wvucomm.sona-systems.com

Once you have a SONA account, use the link below to find our study! https://wvucomm.sona-systems.com/default.aspx?p_return_experiment_id=40 


\author{
Appendix C \\ Experimental Manipulation Instructions
}

\title{
Engagement Condition
}

We want you to spend at least 1 minute reading these directions very carefully:

You are about to watch an episode from the television show Girls. Girls is a comedydrama television series that ran for 6 seasons on HBO (2012-2017). The show follows the lives of four young women living in New York City.

The point of the study you are participating in today is to understand what happens when people are intensely focused while watching television. To help us, we need you to focus on one specific thing.

Research shows that some people appreciate watching television more when they focus on becoming lost in the world of the story. This is what we want you to do. Going forward, try your best to forget everything else and only focus on the story while you watch.

To do this, as you are watching the episode, it is very important that you only think about the story and the characters. We need you to try as hard as you can to immerse your mind into the story world. If you find yourself getting distracted, renew your refocus on becoming absorbed by the story.

Going forward, try your best to forget everything else and focus on the story.

After watching, you are going to be asked about how well you accomplished this task.

When 1 minute has passed and you feel that you understand these instructions, you can continue to the next page.

\section{Self-Referencing Condition}

We want you to spend at least 1 minute reading these directions very carefully:

You are about to watch an episode from the television show Girls. Girls is a comedydrama television series that ran for 6 seasons on HBO (2012-2017). The show follows the lives of four young women living in New York City. After watching the episode, you will be asked to fill out a survey.

The point of the study you are participating in today is to understand what happens when people are intensely focused while watching television. To help us, we need you to focus on one specific thing. 
Research shows that some people appreciate watching television more when they focus on how the story relates to themselves. This is what we want you to do. Going forward, try your best to forget everything else and only focus on yourself while you watch.

To do this, as you are watching the episode, it is very important that you only think about how the story and the characters relate to you on a personal level. We need you to try as hard as you can to connect your life and your past experiences to the story world. If you find yourself getting distracted, renew your focus on yourself and thinking about how the story relates to you.

Going forward, try your best to forget everything else and focus on yourself.

After watching, you are going to be asked to recount how well you accomplished this task.

When 1 minute has passed and you feel that you understand these instructions, you can continue to the next page.

\section{Mixed Directions Control Condition}

We want you to spend at least 1 minute reading these directions very carefully:

You are about to watch an episode from the television show Girls. Girls is a comedydrama television series that ran for 6 seasons on HBO (2012-2017). The show follows the lives of four young women living in New York City. After watching the episode, you will be asked to fill out a survey.

The point of the study you are participating in today is to understand what happens when people are intensely focused while watching television. To help us, we need you to focus on two very specific things.

Research shows that some people appreciate watching television more when they focus on becoming lost in the world of the story. This is what we want you to do. Going forward, try your best to focus on the story while you watch.

To do this, as you are watching the episode, it is very important that you think about the story and the characters. We need you to try as hard as you can to immerse your mind into the story world. If you find yourself getting distracted, renew your refocus on becoming absorbed by the story.

Additionally, research also shows that some people appreciate watching television more when they focus on how the story relates to themselves. This is also what we want you to do. Going forward, try your best to focus on yourself while you watch. 
To do this, as you are watching the episode, it is very important that you think about how the story and the characters relate to you on a personal level. We need you to try as hard as you can to connect your life and your past experiences to the story world. If you find yourself getting distracted, renew your focus on yourself and thinking about how the story relates to you.

Going forward, try your best to forget everything else and focus on both the story and yourself.

After watching, you are going to be asked about how well you accomplished these tasks.

When 1 minute has passed and you feel that you understand these instructions, you can continue to the next page.

\section{No Directions Control Condition}

We want you to spend at least 1 minute reading these directions very carefully:

You are about to watch an episode from the television show Girls. Girls is a comedydrama television series that ran for 6 seasons on HBO (2012-2017). The show follows the lives of four young women living in New York City. After watching the episode, you will be asked to fill out a survey.

When 1 minute has passed and you feel that you understand these instructions, you can continue to the next page. 


\section{Appendix D}

Survey Instrument

\section{Reinforcement of Instructions}

Okay, before you watch the episode, we just want to make sure you understand what you were instructed to do. What did the instructions just ask you to focus on? That is, what is the task you are supposed to do while watching this episode?

[Open-Ended Response]

\section{Section I - Measures for Processes during Viewing and Persuasive Outcomes}

Thank you for watching! Now, while your viewing experience is still fresh, we have some questions about what it was like to watch the episode. Please think about how you felt DURING the episode and answer the following questions:

Narrative Engagement (adapted from Busselle \& Bilandzic, 2009)

(1 = Strongly Disagree; 7 = Strongly Agree; $\mathrm{R}$ = Reverse-Coded)

Narrative Understanding Dimension

1. At points, I had a hard time making sense of what was going on in the program. (R)

2. My understanding of the characters is unclear. (R)

3. I had a hard time recognizing the thread of the story. (R) Attentional Focus Dimension

1. I found my mind wandering while the program was on. (R)

2. While the program was on I found myself thinking about other things. (R)

3. I had a hard time keeping my mind on the program. (R) Narrative Presence Dimension

1. During the program, my body was in the room, but my mind was inside the world created by the story.

2. The program created a new world, and then that world suddenly disappeared when the program ended.

3. At times during the program, the story world was closer to me than the real world. Emotional Engagement Dimension

1. The story affected me emotionally

2. During the program, when a main character succeeded, I felt happy, and when they suffered in some way, I felt sad.

3. I felt sorry for some of the characters in the program.

Self-Referencing During Viewing (adapted from Dunlop, Wakefield, \& Kashima, 2010) (1 = Strongly Disagree; 7 = Strongly Agree) 
1. During my viewing of the episode, the story made me think about my own experiences.

2. During my viewing of the episode, I thought about what it would be like if the events shown in the episode happened to me.

3. During my viewing of the episode, I had thoughts that this story related to me personally.

4. During the viewing of the episode, I was reminded of my own experiences.

Counterarguing (adapted from Nabi, Moyer-Gusé, \& Byrne, 2007)

(1 = Strongly Disagree; 7 = Strongly Agree; R = Reverse-Coded $)$

1. I found myself looking for flaws in the arguments made about HPV in the episode.

2. I found myself actively disagreeing with the characters when they discussed HPV.

3. I found myself actively agreeing with the arguments made in the episode about HPV. (R)

4. It was easy to agree with the arguments made about HPV in the episode. (R)

Now, we would like you to share some of your thoughts and opinions! Please respond to the items below:

Story-Consistent Attitudes: Attitudes towards Talking to Partners about STIs (1 = Strongly Disagree; 7 = Strongly Agree)

1. If I were diagnosed with an STI, it would be irresponsible for me to not talk to my past partner(s) about my diagnosis.

2. If I were diagnosed with an STI, it would be irresponsible for me to not talk to my current partner(s) about my diagnosis.

3. If I were diagnosed with an STI, it would be good for me to talk to my partner(s).

Story-Consistent Behavioral Intentions: Intentions to Talk to Partners (1 = Extremely Unlikely; 7 = Extremely Likely)

1. If you found out that you have an STI how likely would you be to tell your past sexual partner(s)?

2. If you found out that you have an STI, how likely would you be to tell your current sexual partner(s)?

3. How likely are you to have a conversation about STIs with your partner(s) in the near future?

\section{Manipulation Check}

Before you watched the episode, there were instructions displayed about what you were supposed to focus on during the episode. Think back to those instructions. What did the instructions tell you to do? 
I was told to only focus on one thing - the story and immerse my mind into the story-world/feel present in the story-world.

I was told to only focus on one thing - how this story and the characters relate to me on a personal level/connecting my life and my past experiences to the story.

I was told to focus on two things - both immersing my mind into the story world AND to think about how the characters relate to me on a personal level/connecting my life to the story.

I was simply told I would watch a show and answer a survey.

\section{Section II - Measures for the Post-Exposure Period}

Thanks for answering those questions! Now, we would like you please take a minute to think about the episode you just watched.

You can think about whatever comes to your mind that is related to the episode, You will be asked about your specific thoughts at the end of these 2 minutes.

[One-Minute Period]

Thank you for spending time reflecting on the episode. Now we would like to know some more specifics about what you just thought about.

In the boxes below, please write about the different things that you thought about during this reflection time.

Please only put one thought per text box.

You do not have to fill all of the boxes, but you should list as many thoughts as you can that you had during the past 60 seconds.

[Open-Ended Thought Listing]

When people are watching television, they may have different kinds of thoughts. Some thoughts are about the plot, the characters, the actors, and so on. Other thoughts are about the self (i.e., you)!

You indicated you had the following thought: [Participant Thought 1 Inserted Here]. 
Was this thought about yourself and/or your own experience?

Yes

No

You indicated that the following thought was about you and/or your experiences:

\section{[Insert Participant Thought 1 Here If They Selected "Yes"]}

Please explain in detail how or why you think this thought relates to you and/or your experiences.

\section{Section III - Measures of Demographics and Control Variables}

This next section asks questions about the sexual history of you and other people you know. We understand that these questions are very personal and sensitive. Please remember that your participation in this study is voluntary. If you feel uncomfortable answering these questions you can skip them! You will not lose any benefits to which you are entitled if you chose not to answer these questions.

1. Have you ever, at any point, been sexually active (i.e., oral, anal, or vaginal sex)?

$$
\text { Yes }
$$

$$
\text { No }
$$

Sexually Transmitted infections include:

- HIV/AIDS

- Hepatitis

- Trichomoniasis

- HPV (and/or Genital Warts)

- Herpes

- Gonorrhea

- Chlamydia

- Syphilis

- Public Lice (Crabs)

- Bacterial Vaginosis

- Pelvic Inflammatory Disease

- Scabies

- Chancroid

- Molluscum Contagiosum

- Mucopurulent Cervicitis

- Lymphogranuloma Venereum 
2. Have you ever been tested for any Sexually Transmitted Infections (STIs)?

Yes

ㄱo

3. Have you or has anyone close to you ever been affected by a Sexually Transmitted infection (STI)?

Y Yes

No

Finally, please answer a few more questions about yourself.

1. What is your age (use a whole number)?

2. What is your biological sex?

1] Male

$\square$ Female

Other

Prefer not to answer

3. What is the race/ethnicity that you primarily identify with?
a. White/Caucasian
b. Black/African American
c. American Indian/Alaska Native
d. Asian/Asian American
e. Middle Eastern
f. Hispanic/Latino
g. Other
h. Prefer not to answer

4. Before today, how often did you watch the show Girls? (This is the show you just watched).

1] Never

Rarely

Sometimes

Very often

Always

5. Before today, had you ever seen the episode of Girls that you just watched today (“All Adventurous Women Do")?
Yes

No 


\section{Appendix E}

\section{Experimenter Script for Experimental Procedures to Participants}

Thank you all very much for coming to this research study today. Your participation is greatly appreciated.

Today you will simply be watching an episode of a television show and then completing a few survey tasks. You can use the computer mouse to click through the survey. The survey pages are timed and you may not see an arrow to advance to the next part of the survey immediately, so please be patient and take your time reading the instructions.

The point of this study is to learn more about how people process television shows while they are watching. At some points during the study, you may be given instructions about what we would like you to do while you watch. Be sure to read these instructions very carefully and thoroughly before proceeding to each page of the survey. We want to understand how well you are able perform the tasks that the instructions ask you to do.

At this time, I am going to ask you to please turn off your cell phone and stow your belongings. It's very important that you do not have any distractions during the course of this research.

From start to finish, this research study should take you between 45-60 minutes to complete.

When you have completed the survey, the research study will then be finished. To indicate that you are finished, please raise your hand, and I will wrap things up. I will also provide you with a research receipt that you will give to your communication studies instructor if they have agreed to give you credit in exchange for your participation.

Before you begin this research, I want to make sure you are clear about the procedures and your rights as a participant. In front of you is the informed consent form. Please take the next few minutes to read it thoroughly. If after reading the consent form, you decide not to participate, you are free to go. If after reading the consent form you decide to participate, you will need to please sign the form where your signature is requested.

Please note that your participation in this research is always voluntary. You may decide to leave the study at any point in time, without penalty.

Thank you for considering participating in this research. After everyone has decided whether or not they want to participate, I will give you headphones to put on and you will be permitted to begin the study.

At this time, I will give you some time to read the consent form. Please let me know if you have any questions. 
Appendix F

Codebook for Self-Referencing Thoughts

\begin{tabular}{|l|l|}
\hline Thought_List_\# & Participant Thought (for context) \\
\hline Why SR & $\begin{array}{l}\text { Why Participant Thinks It Is Self- } \\
\text { Referencing }\end{array}$ \\
\hline Code & $\begin{array}{l}\text { Is This Self-Referencing to Coder? } \\
\text { If Why SR is Blank }=0 \\
\text { If No }=0 \\
\text { If Yes }=1\end{array}$ \\
\hline
\end{tabular}

\section{What is Self-Referencing, Conceptually?}

Self-referencing occurs when an individual thinks about how the self is involved with information that is presented to them in their environment; it involves their thoughts regarding their past experiences and how they relate to the information More specifically, self-referencing is a way of processing information where the individual relates incoming information to the self or aspects of the self. During this process, a person is reminded of their own experiences while exposed to a message and also compares this incoming knowledge to knowledge that already exist.

- Thoughts regarding past [or present] experiences

- Thoughts of relation to information presented

- Relating information to self

- Relating information to aspects of the self

- Being reminded of own experiences

- Compares knowledge to knowledge that they already have [or don't have]. 
Codebook for Understanding Instructions

\begin{tabular}{|c|c|}
\hline Code & Meaning/Examples \\
\hline 1 & $\begin{array}{l}\text { - } \text { Focus on the story } \\
\text { - Get lost in the world of the story } \\
\text { - Only think about the story and characters } \\
\text { - } \text { Immerse your mind in the story world } \\
\text { - Be absorbed by the story }\end{array}$ \\
\hline 2 & $\begin{array}{l}\text { - } \quad \text { Focus on yourself } \\
\text { - Think about how story/characters relate to you on a personal level } \\
\text { - } \quad \text { Connect your life and past experiences to story world } \\
\text { - Think about how story relates to you }\end{array}$ \\
\hline 3 & $\begin{array}{l}\text { - } \text { BOTH... } \\
\text { - } \text { Focus on the story } \\
\text { - } \text { Get lost in the world of the story } \\
\text { - } \text { Only think about the story and characters } \\
\text { - } \text { Immerse your mind in the story world } \\
\text { - } \text { Be absorbed by the story } \\
\text { - } \text { AND... } \\
\text { - } \quad \text { Focus on yourself } \\
\text { - } \text { Think about how story/characters relate to you on a personal level } \\
\text { - } \quad \text { Think about how story relates to you }\end{array}$ \\
\hline 4 & $\begin{array}{l}\text { - Watch a show and answer a survey } \\
\text { - Watch a show }\end{array}$ \\
\hline 5 & $\begin{array}{ll}- & \text { Other } \\
\text { - N/A }\end{array}$ \\
\hline
\end{tabular}

\section{Codes:}

$$
1 \text { = Engagement Condition }
$$

$2=$ Self-Referencing Condition

3 = Mixed Directions Condition

$\mathbf{4}=$ No Directions Condition

5 = Unidentifiable Condition 